\title{
Nombrar, apropiar. Arqueología del paisaje y toponimia en la aldea de Otíñar (Jaén), ( I 300-2000 DNE)
}

\author{
Narciso Zafra de la Torre*
}

\begin{abstract}
RESUMEN
En la investigación de las dimensiones física, social y simbólica del espacio la Arqueología del Paisaje se vale de múltiples fuentes y métodos. La toponimia medieval y post-medieval es una fuente en la que se pueden rastrear diversos discursos colectivos sobre el espacio: el de la descripción, el de la explotación y el de la apropiación. Por ello se defiende que los discursos toponímicos sirven para conocer las funciones y la significación que sus pobladores otorgaban al paisaje. Este trabajo plantea un modelo de análisis que articula las tres dimensiones del paisaje, enlazando los datos arqueológicos con el origen y distribución de los significados de los topónimos. El modelo se aplica en Otíñar, valle de montaña de la Sierra de Jaén (norte de Andalucía, España), en el que, entre el siglo XIII y el XX DNE, la arqueología y la estratigrafía de los signos revela la superposición de tres capas de significado: el paisaje de los guerreros, el paisaje de los pastores y el paisaje de los campesinos.
\end{abstract}

PALABRAS CLAVE: Arqueología del Paisaje, Teoría de la Arqueología, Toponimia, Jaén.

\begin{abstract}
When investigating physical, social and symbolic dimensions of the environment Landscape Archaeologists pay heed to numerous methods and sources of information. Mediaeval and post-mediaeval toponyms give us important clues about how the land was perceived by different social groups; thus they may be descriptive or reflect its use or its ownership. It can be maintained, therefore, that toponymic descriptions throw light on the uses and meaning with which the occupants imbued the surrounding countryside. We propose here an analytical model which incorporates the three dimensions mentioned above, combining archaeological data with the origin, meaning and distribution of local toponyms. We apply the model to Otiñar, a mountain valley in the Sierra de Jaén in northern Andalucía (Spain), in which from the XIII and XX centuries the archaeology and stratigraphy of these indicators reveal the superimposition of three layers of understanding of the countryside; a land seen by warriors, another used by shepherds and one cultivated by farmers.
\end{abstract}

KEY WORDS: Landscape Archaeology, Archaeology Theory, Toponimy, Jaén.

"De tal manera las palabras llevan la esencia humana de las cosas, que las que no son nombres propios, los geográficos, los toponímicos, llevan un paisaje, y a las veces basta sólo oír la palabra para adivinar lo que puede ser la tierra que recibió aquel nombre."

Miguel de Unamuno

\section{INTRODUCCIÓN}

La Arqueología investiga el Paisaje abarcando las tres dimensiones que se le atribuyen: medioambiental, social y simbólica (CRIADO, 1999: 6), de estas la más difícil de analizar es la dimensión simbólica, y las propuestas de méto- dos o modelos de investigación se han dividido entre los que suponen y asumen una subjetividad inherente en la percepción del fenómeno y por tanto de su explicación (Hodder, Tilley, Shank, Thomas...), y quienes pretenden trascenderlo analizando sus componentes mediante análisis formales y analogías a diver-

* Consejería de Cultura de la Junta de Andalucía. Delegación Provincial de Jaén. Centro Andaluz de Arqueología lbérica. 
sas escalas espaciales y temporales (CRIADO, 1999), o integrándolo en modelos de organización social donde su papel está dado (RUIZ et alii, 200 I). Estos planteamientos se han desarrollado para etapas y culturas muy diversas pero que tienen en común su incomunicabilidad directa, su distancia con respecto a la nuestra.

Sin embargo hay paisajes culturales más recientes en los que se han fosilizado conjuntos de significados que permanecen en la memoria y en los mapas ofreciéndose como la mejor de las fuentes para el conocimiento de la dimensión simbólica del paisaje: la toponimia. En las investigaciones arqueológicas tradicionales la toponimia ha servido a dos propósitos principales: el rastreo de los desplazamientos de los diversos pueblos prehistóricos (indoeuropeos, celtas...) y la localización de asentamientos mencionados en las fuentes (especialmente ciudades clásicas, islámicas, prehispánicas...). Sin embargo en los periodos medievales y post-medievales, hay ámbitos donde los nombres de lugar se han mantenido sobre el paisaje como un manto de símbolos cargado de significados, y en ellos los planteamientos teóricos y metodológicos de la Arqueología del Paisaje permiten ir más allá.

La toponimia, en condiciones de conocimiento exhaustivo, nos sitúa en un universo de saberes, creencias, conceptos y usos que nos guían en la comprensión de la dimensión semántica del paisaje. Scott Nomaday (1974 en BASSO, 1996: 75) ha observado que aprendemos a apropiarnos de nuestros paisajes para pensar y actuar con ellos y sobre ellos, y tramarlos con palabras en los fundamentos de la vida social. En su evolución esta forma de apropiación del paisaje sirve para "comprender que un paisaje particular, completamente lleno de significado pasado y presente, puede ser invocado para 'decir', y que, a través de lo dicho, puede ser invocado para "hacer"' (BASSO, 1996:75). Esta relación entre el decir y el hacer es lo que permite que tras la evidencia de lo hecho podamos seguir el rastro de lo dicho y viceversa. Es mediante este juego de inferencias como, a través de la toponimia, nos acercaremos a la realidad histórica del paisaje.

En este propósito no se parte de la nada, son muchas las disciplinas que se han comprometido con la investigación toponímica y desde la Geografía y la Antropología se han desarrollado programas de investigación de cuyos resultados podemos valernos para abordar el diseño de un dispositivo metodológico adecuado a nuestros propósitos. Los planteamientos analíticos, descriptivos y clasificatorios de geógrafos como Tort (2000, 200 I) contribuyen a situar de un modo ordenado la toponimia en un sistema de conocimiento más amplio, incluyéndola en el discurso académico de análisis territorial. Por su parte la Antropología se ha servido de los nombres de lugar tanto para comprender el universo cognitivo de diversos pueblos ', como para estudiar los cambios toponímicos que acompañan a los cambios políticos (MURPHY y GONZALEZ FARACO, 1996), y, esto es lo más sugerente, para desentrañar el papel de los nombres de lugar en los discursos autóctonos (BASSO, 1996).

Estos acercamientos son interesantes pero no se pueden aplicar sin más. Como muchas otras nuestra especie ocupa y marca el espacio, pero además lo convierte en una parte consustancial de sí misma. La señal espacial de un león expresa un dominio: el territorio le pertenece, por el contrario un vizcaíno, pongamos por caso, está convencido de que es él quién pertenece a Vizcaya y lo expresa diciendo que es de Vizcaya ${ }^{2}$. Lindes, términos y fronteras físicas y simbólicas convierten la tierra (entorno perceptible) en mi tierra (entorno inteligible). La interiorización del vínculo espacial provoca que en el ser humano la apropiación no sea sólo física o socio-económica, sino simbólica. En la mecánica de interiorización del

\footnotetext{
I “Los nombres geográficos son la expresión de los rasgos mentales de cada pueblo y de cada época y, por ello, son también un reflejo de su vida cultural y de las tendencias que identifican cada área cultural" (BOAS, 1934:9 en MURPHY y GONZALEZ FARACO 1996:101).

2 Nuestra lengua consagra esta creencia y el Diccionario de la Real Academia de la Lengua Española en su edición de 2001 recoge como una acepción de la palabra 'naturaleza' la de "origen que uno tiene según la ciudad o país en que ha nacido".
} 
vínculo espacial los nombres de lugar ocupan un lugar preeminente, porque están culturalmente cargados y contienen información tanto física como socio-económica, que los instituyen como un medio universal de apropiación simbólica del espacio. Y, dado que son códigos compartidos, sirven tanto para estrechar los vínculos comunitarios como para organizar los espacios. Esto los hace especialmente relevantes para percibir los ingentes matices de la realidad espacial, cuya complejidad ha orientado los objetivos de investigación de la Arqueología del Paisaje.

Tenemos así unas bases geográficas y antropológicas que se traman con el objeto de estudio de la arqueología mediante un filtro epistemológico extraído de las investigaciones de Foucault. En este punto conviene hacer explícito el camino argumental que ha llevado a elaborar una propuesta de modelo de relaciones entre las dimensiones del paisaje.

\section{NOTAS PARA UNA ARQUEOLOGÍA DEL DISCURSO ARQUEOLÓGICO}

Nada existe a la vista del profano.

A. Moles y E. Rohmer. Psicología del espacio

Hasta que con la revolución ilustrada la ciencia se instituyó como el modo de saber dominante, la metafísica y la filosofía explicaban a la naturaleza como totalidad de lo existente. En un plano superior al de esa NATURALEZA con mayúsculas se situaba una HISTORIA eterna e infinita que cruzando los designios divinos con los hechos de los hombres aspiraba a narrar no solo los acontecimientos del pasado sino también los del futuro y en cierto modo era compendio de todo el saber. Conocía del origen del mundo y de la humanidad con precisión suiza y tenía un instrumento infalible con el que confrontar la consistencia de sus relatos: la Biblia. Había un nexo claro entre naturaleza e historia que concordaba con la idea de creación y designio divino. El conocimiento era uno y la necesidad de conocer estaba íntimamente ligada a la necesidad de creer.
Las ciencias en su especialización escéptica huyeron de la desproporción entre nuestra capacidad de análisis y esa inmensidad. La física apoyada en las matemáticas descollaba como ciencia autónoma, al margen de la filosofía y de la historia, cuyos elementos de prueba de verdad (la Lógica Formal y Dios respectivamente) no eran ya suficientes para demostrar sus postulados. La observación y la confirmación de las predicciones por los hechos se instituyen como fundamentos de la certeza de las teorías. La lógica y la metafísica pierden terreno y de la filosofía se van desgajando parcelas de conocimiento conforme se van imponiendo los planteamientos empiristas. El estudio de la Naturaleza y el estudio de la Historia se separan y si hemos de hacer caso a Horkheimer y Adorno ([1947]|999) esta separación nace con la destrucción por ahora definitiva de los lazos entre el hombre y la naturaleza, y por añadidura entre las ciencias humanas y las ciencias naturales.

Para que este proceso de cambio en el orden del saber se materializase se requerían una condiciones sociales que lo empujasen: la naciente civilización industrial las creó al arrastrar al ser humano a ofrecerse a sí mismo como producto en el nuevo mercado. El proceso de cosificación que esto supone transforma al productor en fuerza de trabajo, al usador en consumidor, pero no sin resistencias, y los movimientos revolucionarios emergen como un contrapeso que organiza las nuevas luchas. Tanto la revolución industrial como los movimientos revolucionarios requieren a las masas como objeto de su acción, y las masas se nutren de seres humanos intercambiables, despersonalizados. Como consecuencia al cambiar la condición del ser humano de sujeto a objeto, tuvieron que cambiar los enfoques y los métodos con los que se le estudiaba.

Según Foucault ([1966] 1999:334-362) este cambio se consuma con la aparición en el siglo XIX de saberes que toman por objeto al ser humano en lo que tiene de empírico, lo que dio origen al conjunto de las ciencias humanas. Este acontecimiento se produjo acompañando a una nueva forma de entender la ciencia, así del estudio de los seres vivos se pasó a estu- 
diar la vida en toda su complejidad; de la investigación de las riquezas a la de las formas de la producción, distribución y consumo; y del análisis de las palabras se pasó a estudiar el devenir del lenguaje. Su investigación detectó que todos los discursos de las ciencias humanas descansan en tres regiones epistemológicas: la biológica, la económica y la lingüística, de manera que:

"El hombre aparece sobre la superficie de proyección de la biología como un ser que tiene funciones - que recibe estímulos (fisiológicos pero también sociales, intrahumanos, culturales) - y responde, se adapta, evoluciona, se somete a las exigencias del medio, compone con las modificaciones que impone, trata de borrar los desequilibrios, actúa según regularidades y tiene, en suma, las condiciones de existencia y la posibilidad de encontrar normas medias de ajuste que le permitan ejercer sus funciones. Sobre la superficie de proyección de la economía, el hombre aparece como un ser que tiene necesidades y deseos, que trata de satisfacerlos teniendo pues intereses, pensando en las ganancias, oponiéndose a otros hombres; en breve, aparece en una irreductible situación de conflicto; esquiva estos conflictos, huye de ellos o logra dominarlos, encontrar una solución que calme, cuando menos en un nivel y por un tiempo, la contradicción; instaura un conjunto de reglas que son, a la vez, limitaciones y vueltas del conflicto. Por último sobre la superficie de proyección del lenguaje, las conductas del hombre aparecen como queriendo decir algo; sus menores gestos, hasta sus mecanismos involuntarios y sus fracasos, tienen un sentido; y todo aquello que coloca en torno a él hecho de objetos, ritos, hábitos, discursos, todo el surco de huellas que deja tras de sí constituye un conjunto coherente y un sistema de signos. Así estas tres parejas de la función y de la norma, del conflicto y de la regla y, de la significación y del sistema, cubren sin residuos todo el dominio del conocimiento del hombre." (FOUCAULT, [1966] 1999:346-347).
El interés para la arqueología de esta construcción teórica de Foucault es doble: por un lado, la coincidencia de las regiones epistemológicas que detecta con los campos de saber que pretende abarcar la disciplina arqueológica; y por otro, la verificación de la adopción por las ciencias sociales de una secuencia de modelos dominantes que es trasladable a la historia de la arqueología. Por primera vez se nos enfrenta a la explicación de porqué entre las dimensiones del paisaje no están la filosófica, la metafísica o la matemática. Nos centramos en un mundo definido por los entornos físico, social y simbólico no porque agotemos con ello el universo observable, como se pretende cuando hablamos de la arqueología total del paisaje (CRIADO, 1999:6), sino porque nos movemos en los límites de los campos epistemológicos de las ciencias humanas, adaptando los discursos y métodos de las ciencias ambientales, sociales y del lenguaje. El proceso de adopción y adaptación de los modelos en nuestra disciplina es el reflejo de la secuencia de influencias dominantes en las ciencias humanas (FOUCAULT, [1966] 1999:349): primero el reinado del modelo biológico que prevalece en la arqueología histórico-cultural (el sistema de las tres edades, el evolucionismo, el difusionismo racista); después la preeminencia del modelo económico que aporta contenidos a buena parte de la arqueología espacial y a la nueva arqueología (marxismo, funcionalismo, procesualismo); y finalmente el lingüístico que domina en la arqueología del paisaje y en la post-procesual (teoría de sistemas, estructuralismo, neomarxismo, neohistoricismo) ${ }^{3}$.

En principio se trata de una ordenación analítica, no histórica y su esquematización es imputable al carácter accesorio de estas notas. Como es natural, abordar con seriedad un análisis arqueológico, al modo foucaultiano, del pensamiento arqueológico exigiría un volumen y no estas líneas. Pero es apropiado consignar la trayectoria de los argumentos desde su origen, de ahí su inclusión.

\footnotetext{
3 Esto nos coloca en el final de un ciclo. La pregunta es iy después?, ¿se iniciará un nuevo recorrido por las diversas etapas biologicistas, economicistas y semioticistas?, ¿se superará en busca de nuevos espacios de conocimiento que hoy se nos escapan?
} 


\section{LOS LUGARES Y LOS NOMBRES: UN MODELO DE RELACIONES ENTRE LAS DIMENSIONES DEL PAISAJE}

El nombre, si avemos de dezirlo en pocas palabras, es una palabra breve, que se sustituye por aquello de quien se dice, y se toma de ello mismo ... es aquello mismo que se nombra, no en el ser real y verdadero que ello es, sino en el ser que le da nuestra boca y entendemiento.

Fray Luis de León. De los nombres de Dios

Se parte de que el estudio de la percepción, los usos y la apropiación de la tierra por parte de sus pobladores se basa en el cruce de las tres dimensiones del paisaje: la física (ambiental), la social (socio-económica) y la simbólica (lingüística). Se produce entonces una interacción entre la dimensión física y la social que se representan en el lenguaje, que es el instrumento para interiorizarla y proyectarla en toda la comunidad, cuya eficacia es directamente proporcional al grado de naturalización e inevitabilidad que se otorga a las relaciones con la tierra y entre humanos.

Estas relaciones se pueden plasmar en un cuadro en el que a las formas de la naturaleza le corresponden unas determinadas funciones que se representan como normas: un escarpe no puede utilizarse como campo de cultivo. Del mismo modo los usos del territorio, las prácticas económicas y sus correlatos sociales, generan determinados conflictos que deben someterse a reglas para asegurar la continuidad del modo de vida: en una huerta no debe entrar ganado y quién lo entre se atendrá a las consecuencias. A su vez el conjunto de las formas y los usos se representan mediante signos en el paisaje, las funciones y conflictos lo dotan de significación y lo sitúan en el universo pensado de la comunidad que mediante normas y reglas es asumido y expresado como un sistema: el mojón de una linde que marca el límite de una propiedad privada.
Cuadro de interrelaciones entre las dimensiones del paisaje y las regiones epistemológicas de las ciencias humanas

\begin{tabular}{|c|c|c|c|}
\hline $\begin{array}{c}\text { REGIONES } \\
\text { EPISTEMOLÓGICAS }\end{array}$ & \multicolumn{3}{|c|}{ DIMENSIONES DEL PAISAJE } \\
\cline { 2 - 4 } & Física & Social & Simbólica \\
\hline Ambiental & Formas & Función & Norma \\
\hline Socioeconómica & Usos & Conflicto & Regla \\
\hline Lingüística & Signos & Significación & Sistema \\
\hline
\end{tabular}

A la estructura binaria tomada de Foucault se ha añadido un tercer término (Formas, Usos, Signos) necesario por no ser el estudio del paisaje un estudio directo del ser humano sino del reflejo del ser humano en sus huellas: los objetos de su entorno, las improntas de sus actividades y los rastros de sus representaciones.

La lectura horizontal del cuadro ilustra sobre los objetos de interés de cada región epistemológica en cada dimensión del paisaje. De manera que la ambiental se ocuparía, en la dimensión física, del análisis de las evidencias sobre el terreno; en la social de su interpretación funcional como partes de un organismo complejo (el paisaje); y en la simbólica de la "naturalización" mediante normas de la asociación forma-función revelando la a-normalidad (imposibilidad) de determinadas prácticas. Por su parte la región epistemológica socioeconómica observaría en la dimensión física los usos del paisaje, las huellas de los asentamientos, de las explotaciones, de las redes de comunicación, caracterizaría por tanto toda esa densa trama que reconocemos como espacio de relación; en la dimensión social se fijaría en las desigualdades en el acceso a recursos, medios y privilegios, destacaría de este modo las fallas en el espacio de relación; en la dimensión simbólica revelaría las reglas que sostienen e imponen los usos abocando a los conflictos. La región lingüística se decantaría en la dimensión física por el estudio de los signos (figuras, señales, distribuciones, etc.) que se reconocen y describen como evidencias con sentido, que, en tanto que son humanas, adquieren significación en la dimensión social, y se articulan como un todo en la dimensión simbólica, donde se conjuga el sistema de relaciones que produce y dirige a la sociedad en su medio. 
Esta lectura superpone el conjunto de las tradiciones epistemológicas de la arqueología, y cada una de ellas elige como objeto de estudio preferente una parte de la realidad (los objetos en sentido lato, la interpretación económica o la búsqueda de significados). Aunque en la historia de la disciplina unas escuelas suceden a otras y las más recientes cuentan con el bagaje de las anteriores, no es aconsejable respetar su aislamiento académico y es preferible buscar la conexión entre ellas en una lectura vertical del cuadro. Así las dimensiones del paisaje engloban las distintas perspectivas de la regiones epistemológicas. De modo que en la dimensión física se hallaría la descripción de las evidencias sobre el terreno (Formas, Usos, Signos); en la dimensión social la interpretación de estas evidencias (Función, Conflicto, Significación); y en la simbólica el análisis de los mecanismos de producción de sentido y de construcción de la realidad cultural (Norma, Regla, Sistema).

\section{I. Formas, usos, signos}

Otiñar es un latifundio ubicado en la Sierra de Jaén, fundado sobre tierras de propios del Ayuntamiento de Jaén, privatizadas en 1827 bajo la condición de fundar una nueva población, la aldea de Otíñar o Santa Cristina, que fue pedanía de la ciudad de Jaén, y quedó abandonada hacia 1980. Los límites de la propiedad están bien definidos y son reconocibles. La finca se formó por la unión de los cuartos del Castillo de Otínar y La Parrilla que suman 1496 has., y antes de la venta de la Parrilla efectuada hacia 1980, las lindes eran las siguientes: Al Norte el cerro del Rajón, el cerro del Frontón y la desembocadura del arroyo de la Parrilla en el río Quiebrajano; al Este la Peña de la Bríncola, el portillo del Pinar, la Nariz del Puntal del Fraile, la Pasada de los Carboneros en la carretera de la Cañada de las Azadillas y el Puntal de Acebuchal; al Sur el cerro del Aguilón del Pollo del Gallego, el cerro de Peña Blanca y el
Cerro Caracoles; al Oeste sigue el límite del término municipal de Jaén con el de Los Villares, entre el Puntalón de la Matilla, el Cerro de la Matilla y Navatrillo (Figura I).

Esta delimitación, obtenida de los últimos pobladores de la aldea de Santa Cristina, coincide con la que se marca en los expedientes de subasta de arriendos de pastos en $1826^{4}$, en la escritura de la propiedad ${ }^{5}$ y en los hitos sobre el terreno. En buena parte está basada en los accidentes geográficos más significativos. A excepción del centro de la linde oriental, todas las referencias se ciñen a los puntos más evidentes del terreno, bien por su forma (Peñón del Sombrero) o por su altitud (Cerro de la Matilla) y se mantiene desde el medievo.

Se encuentra en la cuenca alta del Guadalquivir, $13 \mathrm{~km}$ al sur de la ciudad de Jaén, en plena sierra. Su ocupación obedece a la existencia de un valle excavado en las calizas y las margas por el río Quiebrajano. Éste forma parte de una red fluvial que, encajada en la franja central de la Sierra Sur, alimenta al Río Guadalbullón en su paso hacia el norte buscando al Guadalquivir. Esta red formada por el Río Frío, el Quiebrajano y el Río Campillo (nombre que recibe el Guadalbullón en su curso alto) morfológicamente se caracteriza por insertarse en un relieve definido por la presencia de cerros cónicos, farallones, barrancos y ramblas que en ocasiones conforman estrechos valles de montaña, rodeados de pendientes abruptas, que en algunos casos alcanzan el $70 \%$, con altitudes que oscilan entre los 500 y los 1800 metros. La zona está clasificada en el ámbito climático Mediterráneo continental, con inviernos largos, fríos, poco lluviosos y veranos con temperaturas elevadas y precipitaciones mínimas. Los 600 o 700 mm de lluvia que se recogen al año se concentran en primavera y otoño. Los suelos, de sustrato calizo y margo-calizo, son en general pobres, aunque la abundancia de agua es un factor de corrección para su aprovechamiento

\footnotetext{
4 Archivo Municipal de Jaén, Legajo 196.

5 La escritura de censo de la finca se realizó el 13 de marzo de 1827 ante el notario José María Ruiz. (Archivo Histórico Provincial, legajo 2.356).
} 
en las zonas llanas y bajas. La vegetación actual está compuesta por monte bajo sin arbolado (matorral mediterráneo: garriga, tomillar, espartizal, piornos, aliagas, pendejos...), pinar autóctono o de repoblación (alepensis, carrasco...), restos de vegetación autóctona (encina, alcornoque, quejigo, sabina, cornicabra, cañas, retama, álamos, nogales, etc...), pastizal de montaña, y olivar. Ésta ha sostenido hasta hace poco tiempo una gran masa faunística: lobos, zorros, jabalíes, ciervos, corzos, cabras hispánicas, conejos, ginetas, liebres, lirones, ratas de agua, águilas, buitres, insectívoros y las variedades de peces más comunes. La desecación del río tras la construcción del embalse homónimo, el agotamiento de los acuíferos y demás logros de la civilización han ido haciendo desaparecer algunas, aunque perviven, mermadas, abundantes especies.

Concretamente el valle del Quiebrajano donde se ubica Otíñar participa de estos rasgos con las siguientes características: altitud mínima 540 m, en el cauce del río, en la Rinconada al pie de la Bríncola y altitud máxima I30I m en el Puntal del Bojal. La hidrografía de la zona presenta como principal curso lógicamente al río Quiebrajano que es su principal colector, y aunque la red es de tipo estacional, este río hasta la construcción del embalse homónimo era permanente, recogiendo aguas en su margen izquierda del arroyo de la Hoya del Caño (Barranco de la Tinaja), Arroyo de la Manailla (Covarrón y Barranco de la Cañada) y el Arroyo de la Parrilla, y por la margen derecha el Arroyo de las Azadillas. Al ser de régimen estacional el caudal o, más bien, la propia existencia de los arroyos, depende del volumen de lluvias de cada temporada. En años muy lluviosos se ha llegado a formar una laguna más o menos estable en el Hoyón, 300 metros al norte de la aldea de Santa Cristina. Por su parte las fuentes han sido tradicionalmente muy abundantes y caudalosas, se conocen 18 de las que las principales fueron la del Pozo de la Plaza, la del Covarrón y la de la Cañada del Cortijuelo.

El valle de Otíñar presenta una geoforma simétrica este-oeste y diferenciada norte-sur. El sector norte, cuyo fondo son las Vegas Bajas, es la zona abierta del valle con una distancia entre cumbres de $3 \mathrm{~km}$, un plano de vega de 400 m y un desnivel máximo de $800 \mathrm{~m}$. En él podemos distinguir las siguientes unidades del relieve (Figura 2):

Unidad I. Cimas y escarpes. Se localizan a ambos lados del valle y a lo largo de toda su longitud, marcando la divisoria de aguas. Su característica más visible es la verticalidad que en las zonas (contadas) en que se ve interrumpida conforman los puertos y pasos que comunican el valle con las tierras altas y otros valles. La matriz geológica está compuesta por Calizas del Lías Inferior y medio, fuertemente plegadas $y$, en puntos, muy quebradas (VV.AA., 1987). Su aprovechamiento es limitado, sirviendo básicamente de sombra y abrigo para el ganado, utilizándose esporádicamente para su estabulación. Una utilización marginal, pero significativa, de estas zonas es la explotación del silex, presente en nódulos incrustados en vetas en el plano de contacto entre las margas y margocalizas del Lías Superior y las calizas del Lías Inferior y Medio. La provisión de nieve también fue importante y aún queda el topónimo del Barranco de los Neveros para recordarnos su explotación, férreamente controlada por el Ayuntamiento de la capital hasta el siglo $X X$.

Unidad 2. Vertientes. Conforman un escalón del relieve con un plano de pendiente irregular interrumpido por algunas elevaciones poco destacadas (Cerro de lo Hoyones) su base geológica está compuesta por margas y margocalizas, un paquete gris-pardo comprimido por las calizas del Dogger y las del Lías Medio. Su extensión está ocupada en este momento por olivar y bosque de coníferas, aunque se reconocen trazas de agricultura cerealera muy degradada. Hay que destacar que en esta unidad se han construido dos de las poblaciones que han ocupado el valle (Cerro Veleta en la Edad del Cobre y Santa Cristina en el Siglo XIX d.C.).

Unidad 3. Vegas. Tierras bajas y planas donde tradicionalmente se situaron la mayoría de los labrantíos intensivos, hoy desbancados por un aprovechamiento ganadero intermitente. Son materiales cuaternarios, sustrato con una presencia de clastos importante $y$, suelos profun- 
dos localizados. Su proximidad al río y la posibilidad de regadío dota a esta unidad de unas características que la hacen foco de atracción permanente para las comunidades agrarias. Se reconocen dos líneas de terrazas en la margen oriental y una en la occidental.

En el sector sur, la cuenca de las Vegas Altas, la unidad I (cimas y escarpes) alcanza la máxima extensión, el monte (dolomías y calizas del Lías inferior) se vuelca sobre el valle hasta encerrar a las vegas altas por el sur. Agracejos, bojes, acebuches, cornicabras y sobre todo pinos dominan el paisaje. Aquí los usos forestales y ganaderos son los que se imponen. Por su parte la unidad 2 (vertiente) se convierte en un plano abrupto excavado en las calizas del Dogger con una erosionabilidad muy notoria, su característica principal en su parte este es la omnipresencia de canchales de gran extensión, y en la oeste la localización de los restos muy torturados de calizas del Dogger y el Malm (Cerro del Castillo de Otíñar, Barranco del Toril), núcleo del sinclinal cuya fractura y erosión dio origen al valle.

Por su parte La Parrilla es otro valle de menor extensión que define la cuenca del Arroyo de la Parrilla con una orientación este-oeste y forma rectangular, en el que no existen vegas sino una vertiente (unidad 2) continua en varios planos de pendiente, más pronunciados cuanto más cerca de la cabecera (unidad I) y de la desembocadura del Arroyo. En la actualidad la unidad 2 está completamente ocupada por cultivos de olivar y en el borde de los escarpes resisten agracejos, bojes, acebuches, cornicabras y matorral.

La montaña, omnipresente en Otínar, se hace dominante en el oeste (La Matilla) y en el sur (Peña Blanca y La Nava) y acaba haciendo desaparecer el valle, macizando la cuenca hasta el inmediato valle del Parrizoso que hoy ocupa el embalse del Quiebrajano. Este río, el Quiebrajano, ha excavado las calizas dividiéndolas en dos lados desiguales, la vertiente oriental es más abrupta y más cercana al río, defi- niendo pollos casi inaccesibles sobre los que se dispone el pinar. En la vertiente oeste, de pendientes menos pronunciadas, los escarpes ocupan las cotas más altas. En ella se mantiene el pinar más extenso y explotado de la zona y a la vez la vegetación se diversifica (bojes, acebuches, cornicabras, almeces...), especialmente en los profundos barrancos que, con dirección este-oeste, dirigen las líneas de tránsito hacia las tierras altas y hacia los valles vecinos. La desembocadura de estos barrancos y las mesetas de la vertiente occidental son zonas a propósito para labores de pastoreo delicadas (ordeñar, estabular, ahijar...) el resto de la montaña se utiliza para la alimentación del ganado cabrío y la recolección.

Las formas y usos que se reconocen en el paisaje son representados en la toponimia. A su vez la toponimia esta representada en cartografías y nomenclátor. Esta representación de la representación-del-paisaje implica dos transcripciones: de lo oral a lo escrito y de este a lo cartográfico, lo que supone una doble traición (traduttore traditore) que viene a añadir más incertidumbre a la de por sí compleja investigación de la dimensión simbólica del paisaje. De la cartografía publicada obtenemos los siguientes datos: el Mapa Militar de España escala 1:50.000 (hojas 947 y 969) recoge II nombres de lugar en Otínar; las hojas 947-I y 969I del Mapa Topográfico Nacional, escala I:25.000, 17 nombres de lugar; las hojas (947) I 4, (947)2-4, (969) I-I y (969)2-I del Mapa Topográfico de Andalucía E. I:10.000, contienen 20 topónimos, que se reducen a 7 en el Mapa de Clasificación de Suelo E. 1:5000, del Consorcio para la Gestión e Inspección de las Contribuciones Territoriales del término Municipal de Jaén. Esta escasez es fruto en parte de la escala y en parte del desinterés, pero en todo caso no es una realidad analizable de la que extraer conclusiones, lo que ha obligado a recopilar de fuentes históricas y sobre todo orales ${ }^{6}$ un conjunto de 250 topónimos para un espacio de $15 \mathrm{~km}^{2}$.

\footnotetext{
6 El interés y la memoria de mi padre, Cándido Zafra Buitrago, natural de Otínar, ha sido la fuente principal de procedencia de los topónimos. Su solvencia como informador se la otorga su niñez de pastor y los 52 años de agente forestal en la Sierra de Jaén.
} 
A la recopilación de los nombres de lugar sigue el análisis de su distribución, con tres enfoques que atienden respectivamente a la distribución espacial del topónimo, a la distribución de los campos semánticos representados en él o a la distribución espacial de sus significados.

Sin la información decisiva que aporta el nombre de lugar sería muy valioso realizar un análisis espacial cuantitativo de la distribución de los topónimos (métodos de cuadrados, o distancias, vecino más próximo, etc.) que nos llevaría a detectar lo que ya sabemos, es decir que los topónimos se concentran en las tierras de cultivo y en la población y que cuanto menos explotada está la zona menos nombres de lugar presenta. Esta concentración es consistente con el principio de place-name partitionship de Basso (1984): "un incremento demográfico en un espacio produce nuevos topónimos que sirven para nombrar y diferenciar nuevas partes de él" (en MURPHY Y GONZÁLEZ FARACO, 1996, 102). La anonimia espacial es inversamente proporcional a la presión demográfica, pero esta presión afecta de modo desigual a los espacios ya que la mayor parte de los topónimos se concentran en el núcleo residencial y en los campos de cultivo (Figuras 3 y 4), esto indica que no estaría de más unir al principio de divisibilidad de Basso un principio de distribución de los topónimos que contemplase la presión de la producción y de la propiedad como un factor determinante en la concentración de los nombres de lugar en determinados ámbitos.

En los estudios toponímicos tradicionales se ha admitido convencionalmente como significativa la distribución de los topónimos y se han ocupado de clasificar los nombres de lugar atendiendo a los campos semánticos en los que se encuadran: Orónimos (cerro, barranco, puntal...), Hidrónimos (fuentes, lagunas, rio, arroyo, pilillas), Fitónimos (madroñal, espartal, bojal, matagallar), Zoónimos (del Lobo, de los Caracoles, de la Burra, de la Yegua, del Águila), Antropónimos y Patronímicos (C/ Jacinto Caña- da, C/ Juan Antonio Martínez, Chiripa de Matías Soler), topónimos de actividades económicas (ganaderos: puntalillo de la sal, cuartos, los machos, Majada de los Carneros, Cueva del Toril, La Vaquería... Agricolas: La Eras, Huerta de Juan María, Vega de Juan Manuel, etc), Odónimos (Carretera de Jaén, camino de la Cañada de las Azadillas...), Hagiónimos (C/ de San Fernando, Cinta del Fraile, Plaza de la Virgen de las Mercedes, Puntal del Púlpito), topónimos históricos (Castillo de Otínar, Fuente de los Ballesteros, Peña de la Bríncola...), dejando abierto un campo Varios para los que no encajan en el resto ${ }^{7}$.

Esta manera de establecer distribuciones deja de lado la propia dimensión espacial del fenómeno, lo que ha generado versiones más sofisticadas, como la que propone Tort (2000), que también agrupan los topónimos por su significado pero considerando relevante su distribución espacial e interpretando a través de esta la organización del territorio. Este enfoque geográfico permite la construcción de una especie de mapa onomasiológico donde se distribuyen los topónimos por "niveles de significación" o "grupos onomasiológicos", interpretando el territorio mediante la detección de la preponderancia de cada grupo (orónimos, hidrónimos, odónimos, etc.) y considerándolos factores que explican el origen de determinada localización. Esta fórmula está basada en lo que Tort (2000: 4 y nota 9) denomina "principio de significatividad territorial" que predica que "en condiciones homogéneas de espacio y de tiempo, una serie de topónimos afines de un determinado territorio tienden a reflejar los aspectos geográficamente más significativos de este territorio". Los condicionantes son quizás excesivos (la cursiva que los delata es mía), y aunque aporta información sobre determinadas características o cualidades del paisaje, se aprecia que la separación entre estos grupos de significados dispersa la integridad de lo que podríamos llamar discurso toponímico, del mismo modo que cuando agrupamos los objetos arqueológicos atendiendo a su materia prima (cerá-

6 He tomado esta clasificación de Alcázar, A y Azcárate, M. (1998). 
mica, hueso, piedra...) y no atendiendo a su función (v.g. partes de diversos materiales que conforman un telar). Sin embargo es innegable su utilidad en estudios de marco territorial amplio.

Pero lo que interesa fundamentalmente en esta investigación es el estudio de la representación que del paisaje se hace en la toponimia, que supone un primer nivel de acercamiento a las concepciones que se tienen sobre la tierra que se habita. El sentido surge del conocimiento del objeto (paisaje), del signo (toponimia) y de las relaciones entre ambos. Las formas y los usos del paisaje que hemos descrito se reflejan en la toponimia de acuerdo con un orden lingüístico que distingue entre dos términos: el nombre común que atiende a la diferenciación de las formas del paisaje y el nombre propio que se ocupa de su señalamiento particular ${ }^{8}$. El primero reconoce una forma del paisaje (cerro, puntal, vega, calle, collado, camino, barranco...) y tiene un valor denotativo (significativo), el segundo la individualiza adscribiéndola a un rasgo definitorio (similitud, contigüidad, uso, pertenencia...) y tiene un valor connotativo (asociativo). Agrupando por el elemento genérico accedemos al universo de entidades geográficas que reconocen los habitantes de Otíñar: cerro, puntal, barranco, fuente, laguna, río, arroyo, pila, puente, majada, era, huerta, cabezada, camino, carretera, calle, casa... Si nos fijamos en el específico detectaremos las relaciones dominantes en la identificación del lugar: pertenencia en las casas y cultivos (Vega del Amo, Casa de Tía Virginia, Hoyo de Cándido el Alcalde), presencia en la montaña (Matagallar, Poyo del Espartal, Barranco de los Lobos...), destino en los caminos (camino de la Cañada de las Azadillas, Carretera de Jaén...). Convencionalmente se ha admitido esta distinción entre nombre común y nombre propio como muy significativa ${ }^{9}$, sin embargo por definición todos los topónimos tienen un valor denotativo. Primero porque difícilmente se presentan topónimos que sean sólo nombres comunes o sólo nombres propios, nos encontramos por regla general ante la Cueva (común) de los Bastianes (propio), el Cortijo (común) del Amo (propio), el Collado del Cuchillejo o la Calle de San Fernando; y segundo, y esto es lo importante, porque todos los topónimos tienen un significado en tanto que ocupan un lugar en el discurso simbólico que sobre el paisaje sostienen las comunidades que lo habitan. Ese discurso es el que se intenta revelar.

De manera que tratando cada topónimo como una unidad de significado podemos llegar a establecer relaciones más o menos evidentes con lo que designa (contigüidad o semejanza por ejemplo), y además, y esto es lo más importante, podemos investigar la toponimia como un discurso, un conjunto de enunciados (Foucault, [1969] 1970, capítulo III), cuya función es dotar de sentido al paisaje.

\subsection{Función, conflicto, significación}

Si volcamos los topónimos sobre el plano observamos que la distribución no es uniforme ni constante (Figuras I, 3 y 4), a pesar de ello existe un orden en esta distribución de los nombres de lugar que supone una interpretación del espacio que responde a pautas reconocibles. Nos encontramos con una concepción del valle como espacio cerrado ${ }^{10}$ con puertas de acceso (Puerto Blanco, Puerto de la Hoya, Puerto de la Bríncola, etc.), líneas de tránsito (Carretera de Jaén, Camino de la Cañada de las Azadillas, veredas, sendas, pasadas...) y parajes, cada

\footnotetext{
8 En los estudios toponímicos también se utiliza "elemento genérico" para referirse de modo general a la entidad geográfica y "elemento específico" para referirse al elemento del topónimo que identifica de manera particular a la entidad geográfica. Un glosario útil para los investigadores puede consultarse en la Base de Datos Toponímicos de la Comunidad Autónoma del País Vasco: http://wwwl.euskadi.net/euskara_eaetoponimia/bin/consultar/Glosario I.apl\# I 2.

9 Ullmann (1967: 87) indica que "la diferencia esencial entre los nombres comunes y los propios estriba en su función: los primeros son unidades significativas y los segundos son meras marcas de identificación".

10 La Cinta del Fraile es el límite oriental, el Cerro de la Mata el occidental, ambos topónimos aluden a límites: la cinta en su acepción antigua de muralla (D.R.A.E. 1899), la Mata en la suya de bosque o selva.
} 
uno de ellos con sus peculiaridades toponímicas: las parcelas con nombres de los poseedores, las calles con nombres de los propietarios y de los santos protectores, el monte con nombres descriptivos, etc. La interpretación del mundo que late tras esta forma de nombrar a los espacios es la de un sistema que impone el discurso de la apropiación como el más significativo, el dominante. Para nombrar un lugar se precisa señalarlo, marcarlo para uso de una comunidad establecida, es un discurso interno donde conocer a quién corresponde cada espacio es un pre-requisito para la supervivencia. Se vislumbra así un espacio definido por barreras físicas, sociales y simbólicas: las formas del paisaje proscriben determinadas usos (los escarpes no permiten la agricultura), pero son las prácticas culturales de la comunidad las que prescriben las funciones que son asumidas y transmitidas (el ganado se abriga en ellos). La función no está dada por la forma, sino que es asignada en el reparto socioeconómico que de ese paisaje hace el modo de vida de los otiñeros.

El modo de vida "l campesino en la Otíñar contemporánea se caracteriza por la formación de una comunidad de colonos campesinos arrendatarios dentro de un latifundio. Circunstancia que implica que la comunidad se constituye después, dentro y bajo la gran propiedad. Después porque aunque la corona impone para que se produzca la desamortización de Otiñar en el siglo XIX la construcción de la aldea y el establecimiento de 15 familias de colonos, en 1845 esto aún no se había cumplido; dentro porque los límites de los términos de la aldea, su territorio de explotación, eran los límites de la propiedad latifundista menos las tierras de explotación exclusiva del terrateniente; y bajo puesto que el derecho a explotar la tierra lo obtenía cada colono mediante una relación contractual con el propietario, que le arrendaba casa, tierra, pasto y otros derechos de uso.

La consecuencia principal es que el acceso a la tierra no lo otorga la pertenencia a una comunidad sino una relación, en principio, estrictamente económica con el amo. Esta situación cambia en dos generaciones por la dinámica reproductiva de una población que deviene endogámica y que consigue que de un grupo de colonos que se vinculan uno a uno con el propietario se pase a una comunidad de campesinos entrelazada por vínculos de parentesco y vecindad, que tiene derechos sobre determinadas tierras, otorgados en origen por el contrato pero ya también por la costumbre y el reconocimientos de los convecinos. La comunidad campesina es una respuesta adaptativa a las leoninas condiciones de asentamiento impuestas por el primer barón de Otínar, y entre sus funciones desarrolla la de resistirse al dominio absoluto de la propiedad sobre la tierra. Nos encontramos en el propio origen de la aldea un conflicto larvado entre la propiedad latifundista y los arrendatarios minifundistas, que impregnará todas las relaciones económicas y sociales, que estallará durante la Guerra Civil y que será causa de la desarticulación de la comunidad en la posguerra y del posterior abandono del valle. Si, como defendemos, la toponimia es un discurso relevante, este conflicto debe estar presente en ella. Lógicamente no se puede esperar una presencia evidente con asociación inmediata, dadas las condiciones de desigualdad y sometimiento en que se expresa y hay que rastrearlo en formas más sutiles.

Quizás la expresión más notable de este conflicto en la toponimia lo encontramos en la doble denominación Otínar o Santa Cristina, nombre este último que aparece constantemente en la documentación escrita y nunca en las conversaciones de los antiguos habitantes de Otínar. Otínar es el nombre medieval del mayor de los dos valles que forman el latifundio, Santa Cristina es el nombre oficial otorgado en I83। por la reina Doña María Cristina de Borbón, ambos se simultanean en letra impresa (Madoz, cartografía ...) y fuentes documentales (Actas capitulares, protocolos notariales...), sin embarII El concepto de modo de vida es definido por Iraida Vargas (1990:64) como las "respuestas sociales de un grupo humano a las
condiciones objetivas de su objeto de trabajo". 
go no fue usado por los otiñeros, gentilicio este que, por cierto, nunca fue sustituido por el de santa cristinenses. Se puede colegir una separación entre el topónimo oficial preferido por los propietarios y las administraciones y el tradicional por el que se inclina el pueblo, preferencias que representan una resistencia a admitir un cambio impuesto desde arriba, que venía a modificar un hecho vigente desde al menos 500 años antes. Hasta 1939 los dos topónimos coexisten en la mayor parte de los documentos, incluso durante la Segunda República se acuño un sello, el único que conozco de la población, con el lema Alcaldía Pedánea de la Aldea de Santa Cristina (Otiña) (sic) lo que informa de la persistencia del topónimo primigenio y de la insistencia de la administración. Tras la guerra civil los propietarios de Otíñar, una vez fracasada la experiencia colectivista republicana, reinstauran su poder, y libres ya de la obligación de vincularse con la población medieval de Otínar por la necesidad de legitimar la privatización, y como parte de la desarticulación de la comunidad campesina vencida en la guerra, propician el nuevo bautizo de la propiedad que pasa oficialmente de ser Aldea de Otínar a Hacienda Santa Cristina. No es ya una aldea sino una hacienda, no habrá más una comunidad campesina sino un latifundio explotado con jornaleros eventuales. Esta situación no se produce después de que la comunidad se desintegre sino como parte del proceso de destrucción de la misma, negándola aún viva.

Éste es el ejemplo más visible de la larga escenificación del conflicto entre la comunidad y la familia propietaria que arranca con la propia colonización y se mantiene activo hasta la desposesión de los colonos cinco generaciones después. Sin embargo la expresión más firme y continuada de este enfrentamiento es la propia existencia de topónimos que indican pertenencia y denominan a las casas y tierras asignadas en arriendo a los colonos y sus descendientes (la Casa de Tía Virginia, la Vega de Juan María), poniéndolas en pie de igualdad con las que son explotadas directamente por la familia propietaria (la Casa del Amo, la Vega del Amo). Este modo de hablar de los lugares contradice el sistema de relaciones dominado por la existencia de una propiedad única, que, aunque no es directamente contestada hasta la Segunda República, si ve como los derechos de apropiación y explotación de las familias arrendatarias van limitando los suyos. Esto es trasladable asimismo al núcleo residencial donde los nombres de las calles hacen referencia hasta 1893 a las imágenes protectoras (San Fernando y la Virgen de las Mercedes) y después a los antepasados de los propietarios (Calle de D. Jacinto Cañada y Plaza de D. Juan Antonio Martínez), este cambio amén de remarcar el dominio privado de los espacios de uso público fijan el Don como un tratamiento que mantiene las distancias sociales aún en la denominación del propio domicilio, justo cuando la comunidad consolida sus derechos frente al terrateniente. Por su parte los otiñeros no admiten este modo de llamar a sus viviendas y por ello nunca van a la Calle de Don Jacinto Cañada n ${ }^{\circ} 12$ sino a la Casa de Tía Virginia, con lo que, en un impecable ejercicio dialéctico, al espacio común el nombre se lo impone la propiedad y al privado la comunidad.

La supervivencia campesina exige un alto precio que hay que pagar primero al señor para que permita el acceso a la tierra y después a la tierra para extraerle los frutos. Por ello los nombre de lugar nos revelan junto al conflicto social, una lucha de otro orden: la que enfrenta a los campesinos con la naturaleza. En realidad ambas nos remiten al leitmotiv del pensamiento campesino: el trabajo, en su doble acepción de esfuerzo y penalidad ${ }^{12}$.

En Otínar el núcleo central (el poblado y los cultivos aledaños en las vegas planas y las laderas) con su toponimia característica alusiva a la apropiación (la vega de, la casa de, las olivas de...), se ve rodeado por un anillo montañoso con nombres no menos característicos:

\footnotetext{
12 La lucha contra la naturaleza como la lucha contra el amo son evidencias de una mentalidad donde domina la necesidad de la apropiación: se lucha contra lo que impide que nos apropiemos lo que necesitamos.
} 
Cerro del Frontón, Cerro Veleta, Peña de la Bríncola, Cinta del Fraile, Los Madroñales, Peña Blanca, Cerro de la Matilla, Cerro de la Mata, Salto de la Yegua y Los Reventones, salvo la Peña de la Bríncola, la Peña Blanca y Los Madroñales cuyo origen trataremos más adelante, todos lo topónimos aluden a límites (Cinta, Frontón, Mata, Matilla, Veleta) o esfuerzos (Salto, Reventones), conceptuando estos ámbitos como hostiles: el monte, lo que escapa al control y se resiste a los trabajos agrarios. Hay que añadir que estas denominaciones no son exclusivas del límite sino que en el cuadrante suroeste, el más montañoso, encontramos el Barranco de los Lobos, el Barranco de los Corzos, la Piedra del Águila o la Víbora en la montaña más impenetrable, con lo que el universo salvaje se funde con el silvestre conformando una imagen homogénea de lo amenazante. Le-Roy Ladurie (1981: 439-44I) descubrió que a principios del siglo XIV en Montaillou, aldea occitana, los campesinos habían distribuido en torno al poblado los zoónimos de acuerdo con un orden concéntrico, en el que los animales considerados positivos rodeaban el pueblo y los negativos, las alimañas, eran ubicadas en la periferia. Esto puede parecer un exceso en la búsqueda de sentido en el paisaje ya que por lógica los animales no domesticados se alejan de los poblados y por ello donde se les observa y donde se puede establecer el topónimo alusivo es en los márgenes. Sin embargo eso no es óbice para que en el universo simbólico campesino la asociación controlado-bueno no-controlado-malo sea una presencia constante y se refleje en el modo en que se dota de significado al paisaje, produciéndose una interacción entre un microcosmos de referencias y un macrocosmos de sentidos, que es el mecanismo, si se quiere psicológico, que vincula los lugares con las palabras otorgándoles su significación particular ${ }^{13}$.

Roy Wagner (1986:16) considera que el paisaje es investido con significado mediante la interacción dialéctica entre un "microcosmos de nombres" y un "macrocosmos de comunicación e interpretación viva". Podemos proponer que el topónimo, como parte del microcosmos de referencias, dota de sentido al lugar al incluirlo en el discurso colectivo sobre las funciones del espacio, se acerca de este modo a la definición de símbolo práctico de Bueno (1980):

"en el concepto de símbolo práctico destacaríamos como característica genérica esencial su naturaleza 'técnico cultural' (institucional por ejemplo) en virtud de la cual diremos que los símbolos son causados (o producidos) por la actividad (lógica, tecno-lógica) humana y, a la vez son de algún modo causantes o determinantes en algún grado del objeto al cual simbolizan"

De manera que el símbolo, en este caso el topónimo, y el objeto, en este caso el paisaje, interactúan, es decir, en la comunidad que lo crea o recrea el topónimo puede explicar el paisaje y este a su vez el topónimo, pero no por un nivel asociativo-descriptivo básico (como en Peña Blanca o en Cerro de la Noguera) sino porque para comprenderlo hay que compartir el código que los incluye como parte del universo simbólico de la comunidad. Por ejemplo, si un Apache Occidental nos dice que el nombre de cierto paraje de su tierra es Tsee Ligai Dah Sidile esto es suficiente para designarlo y utilizarlo aun desconociendo su traducción y etimología, pero si comprendemos su lengua descubrimos que significa Las-Rocas-BlancasQue-Están-Tumbadas-Formando-Un-Grupo-Compacto, y si además conocemos su modo de nombrar los lugares, anotaremos que es una descripción exhaustiva del lugar desde una determinada perspectiva, y esto es muy importante porque los nombres de lugar apaches "implícitamente identifican posiciones para ver esas localizaciones: posiciones óptimas, por así decirlo, desde las que los sitios pueden ser obser-

13 Almudena Hernando (1999: 31), en su acercamiento a las formas prehistóricas de representación opina, siguiendo a Olson (I994: 167), que aquella parte de la realidad que no se controla se representa metonímicamente y la que se domina metafóricamente. La comprobación de esta hipótesis con la toponimia de Otíñar demuestra que en esta comunidad campesina contemporánea no se cumple. Todos los nombres de lugar pueden entenderse como metáforas de lo controlado (Casa de Tía Virginia, Vega de Juan María, Cortijo del Amo) y de lo no-controlado (Barranco de los Lobos, Barranco de los Corzos, Puntal del Bojal, Cerro de la Mata). 
vados, clara e indudablemente, tal y como su nombre los describe" (BASSO, 1996:89). Esto último nos acerca al discurso espacial de una comunidad de origen nómada que es muy distinto del de los campesinos y del nuestro, dado que todos están mediatizados por su función.

Por tanto la elección del topónimo no es casual, obedece a la necesidad de situar cada punto significativo del espacio en el lugar que le corresponde en el universo semántico de los pobladores, luego su aparente arbitrariedad está cargada de motivos. Refiriéndose a la representación del signo durante los siglos XVII-XVIII, Foucault ([1966]1999:68) escribe: "lo arbitrario es medido por su función y sus reglas son muy exactamente definidas por ella. Un sistema arbitrario de signos debe permitir el análisis de las cosas en sus elementos más simples; debe descomponer hasta llegar al origen; pero debe mostrar también como son las combinaciones entre estos elementos y permitir la génesis ideal de la complejidad de las cosas". Esto es aplicable punto por punto a la manera de dotar de nombres a los lugares: los nombres comunes des-componen el paisaje en sus elementos constitutivos (cerro, barranco, vega, río, collado...) y, a la vez, lo ligan en una construcción mental ad hoc: la ladera del cerro es la vertiente del barranco, el collado no se entiende sin la montaña, el valle sin el río, etc. Si el paisaje es un continuun con particularidades reseñables, entonces el cerro no tiene unos límites precisos que lo separan del resto del valle, al modo en que la silla es independiente del suelo, sino que es parte de una totalidad compleja clasificable y diferenciable pero indivisible como forma. A su vez el nombre específico responde a la necesidad de delimitar ámbitos de apropiación, de control o, al menos, de reconocimiento, y señala, con denominaciones más o menos arbitrarias, cada una de las formas del paisaje que reconoce como aislables.

La arbitrariedad y la complejidad son dos características inquietantes, incluso contradictorias con la función denotativa del nombre de lugar, que debe fijar términos, distinguir, señalar, en definitiva determinar. Pero siguiendo a Bueno (1980) en su conceptuación de símbolo práctico "ese halo de indeterminación o impre- cisión que atribuimos al objeto del símbolo práctico, no brota tanto de nuestra ignorancia del objeto (...) sino que es el objeto mismo el que es indeterminado e incompleto, pero en tanto que su determinabilidad depende de la propia actividad práctica humana que se ejerce a través de la interpretación del símbolo", es decir, el lugar (el objeto) está incompleto sin el nombre (el signo) que lo identifica, y lo sitúa en el discurso espacial de la comunidad. Por consiguiente la función de los lugares está directamente vinculada con su significación y por ello con el modo de nombrarlos, y esa misma función los sitúa en la trama de las relaciones socioeconómicas, de las que deben ser un reflejo. Lo que nos lleva a plantear interpretaciones que superan la descripción que nos aporta la clasificación de los topónimos en tipos onomasiológicos (que aluden a las diversas maneras de nombrar las formas del paisaje, las actividades económicas, etc.), de modo que podemos atender a su distribución espacial (reflejo de su función) y a su significación en el sistema de relaciones socioeconómicas. Pero es posible ir más allá y penetrar en la fuente misma de producción de significados: el sistema.

\subsection{Normas, Reglas, Sistema}

La percepción de las cosas y de las relaciones físicas entre las cosas se produce dentro de un universo de formas que es el primer contacto con la realidad exterior. En tanto que el interés por las formas no es gratuito, las asociamos con usos, y su utilidad les da sentido disponiéndolas en una red de representaciones simbólicas que permite su comunicación y transmisión, que crea el universo compartido: el sistema. De manera que el sistema es el mundo, la realidad, y nada escapa a su influjo. El sistema asegura la conciencia histórica de una raíz común y de una continuidad cultural que se apoya en discursos a los que es relevante preguntar sobre sus orígenes, temáticas y causas de perduración y, como es natural, sobre sus apropiadores.

En el universo de los últimos otiñeros que rastreamos en los nombres de lugar se encuentran, con la toponimia propia de la última ocu- 
pación, un conjunto de topónimos heredados de los discursos de los anteriores pobladores. El mantenimiento de los topónimos es indicio de continuidad en el poblamiento, lo que no significa estabilidad sino conexión entre las diversas situaciones. El "residuo" toponímico de cada situación no es casual, está directamente decidido por el nuevo discurso. Distinguimos así tres horizontes bien definidos: un primer estrato de origen medieval fruto de una primera colonización castellana (s. XIII-XV), uno segundo de uso y no de ocupación permanente, que erosiona ese estrato de base y el tercero, dominante, que procede de la segunda colonización (s. XIX y $X X$ ) y que, aunque parcialmente, nos transmite todos los demás. De este modo hemos identificado tres horizontes en el paisaje de Otínar: el paisaje de los guerreros, el paisaje de los pastores y el paisaje de los campesinos.

\subsection{El paisaje de los guerreros}

Cuando este valle es conquistado por Fernando III, posiblemente poco antes de la toma de Jaén en 1246, como parte de su campaña de devastación para aislar y rendir la ciudad, ya no había población islámica en él, esta es la causa de la inexistencia de topónimos de origen árabe en Otínar y la escasez de los mismos en toda la Sierra de Jaén. Esto contradice una opinión extendida y merece comentario. Se ha escrito que Otínar es palabra árabe que significa 'hacer luz' (LÓPEZ PÉREZ, 1989; LÓPEZ ARANDIA, 2001:48; OLIVARES BARRAGÁN 1988: 37) ${ }^{14}$, esta interpretación se basa en una comunicación personal que "un catedrático de Historia del Arte en la Universidad de El Cairo" hizo a José Rodríguez de Cueto por entonces dueño de Otíñar (BENE-
DICTO, 1953:228 en LÓPEZ ARANDIA, 200 I:48), sin embargo podemos aportar otra línea de interpretación que otorga la responsabilidad del topónimo a los conquistadores cristianos del siglo XIII. Se basa en una visión del conjunto de los topónimos del entorno (Bríncola, Peña Blanca, Barbarin, Codes, Orosco, Alta Coloma, Valdearazo, Zarbel, Zumbel...) que remiten a un área muy concreta del norte peninsular: Navarra y Guipúzcoa.

Hay un Otiñano municipio de Navarra en el Valle de Aguilar, merindad de Tierra Estella (UTM X 557800, Y 47। 9450, Z 684) '5; Bríncola, acantilado al noreste de Otínar, es un topónimo de Legazpi (Guipúzcoa); el Cortijo de Pedro Codes que se encuentra $4 \mathrm{~km}$ al norte de Otíñar tiene su paralelo en la Sierra de Codés (Torralba, Navarra) que es el telón de fondo de Otiñano; Peña Blanca en el sur de Otínar tiene varios paralelos en Navarra, encontrándose el más cercano al suroeste de Etayo, también en Tierra Estella; La Parrilla, valle norte de Otíñar, es también un paraje de Genevilla, al oeste de Codés (Tierra Estella, Navarra); Zumbel o Zumel, cerros entre las Peñas de Castro y Otínar, se asemeja a Zumabel (o zumabeltz) que es un paraje en el municipio de Orísoain en Navarra; Orosco, cerro al norte de Campillo de Arenas tiene su correspondencia en el Valle de Orozco entre Vizcaya y Álava (UTM X 505825, Y 4772500), Barbarín (barranco de Arbuniel) es un paraje del municipio de Cirauki en Navarra y un municipio al sureste de Peña Blanca asimismo en Tierra Estella; Alta Coloma sierra al sureste de Campillo de Arenas tiene su réplica parcial en Mendaza (Tierra Estella, Navarra) ${ }^{16}$. Por otra parte Valdearazo, que es nombre del curso

14 Otra argumentación es la de Eslava Galán (1989:19) que defiende que Otínar deriva de atorimar, término citado en la crónica de la conquista. El diccionario recoge atorigar como 'prender, encarcelar', pero se me escapa cual es la secuencia de transformaciones que convierten A-to-ri-mar en O-tin-nar (que es como figura en las primeras fuentes).

15 En http://www.rutasnavarra.com/asp/asp_glos/glosario.asp se atribuye a Julio Caro Baroja su significado como lugar propiedad de una persona llamada 'Otiñ-'. De 'Otiñ-' más '-ano', siendo el primer elemento un nombre de persona no identificado y el segundo un sufijo que indica propiedad. Se añade que los siguientes nombres de persona pueden formar parte del nombre de la localidad: Otincius, Otilius y Otindius (documentados) y Otinius y Otinianum, sin documentar. Como no se ha podido comprobar la referencia se incluye a título de curiosidad.

16 La existencia de los topónimos navarros se comprobó a través de la Base de Datos de Toponimia Oficial de Navarra (http://toponimianavarra.tracasa.es/base.aspx?lang=cas), su localización fue posible a través del Sistema de Información Territorial de Navarra (http://sitna.cfnavarra.es/navegar/toponimo.aspx?lang=cas\&id=8429l), de cuya cartografía se han extraído todas las coordenadas. Por su parte Brinkola, se localizó a través del 1:5000 web de la Diputación Foral de Guipúzcoa (http://b5m.gipuzkoa.net/liz5000/). 
alto de Río Quiebrajano, sería el valle de la disputa (en euskera 'arazo' significa problema); Zarbel, localizado inmediatamente al suroeste de la población de Campillo de Arenas significa "alegre" en vasco y es nombre de pila en esta lengua. Naturalmente ese conjunto de topónimos de procedencia vasco-navarra sólo pueden deberse a la colonización castellana ${ }^{17}$ (Figuras 5 y 6). Esta toponimia nos sitúa por tanto en el momento de la conquista, y para quienes decidieron los nombres que se otorgarían a los lugares estaría presente la evocación de los de procedencia, práctica colonial muy socorrida que ha multiplicado en las tierras de conquista los topónimos de las de origen de los conquistadores. Otros nombres de lugar que podrían suponerse de origen árabe como el Cerro del Calar, con un pequeño castillo (qalat) sobre un canchal de caliza, pueden ser castellanos puesto que 'calar' es precisamente un lugar en que abunda la piedra caliza; caso similar es el de Las Alcandoras, pues con ser palabra latina arabizada, sin embargo es también castellana y por tanto podía ser impuesta por los conquistadores.

La defensa del origen árabe del topónimo se enfrenta también a la toponimia histórica recogida en las fuentes andalusíes. La toponimia de época islámica que se conoce de la Sierra Sur se concentra en el siglo $X$, durante la primera fitna, y acompaña al relato de la campaña de Muntilun, emprendida por Abd Al Rhaman III para someter a los levantiscos señores muladíes encastillados en las tierras altas del subbético. La mayor parte de los topónimos no han sido ubicados con seguridad y los diversos autores que los interpretan no se ponen de acuerdo sobre la mayoría (AGUIRRE Y JIMÉNEZ, 1979; OLMO, 1997 y 200 I; SALVATIERRA, 200 I). En todo caso todos los que han perdurado o han conseguido el consenso de los investigadores no pertenecen a esta parte de la sierra.

La primera fuente toponímica cristiana que nos interesa es El Libro de Montería de Alfonso XI (MONTOYA, 1992) ${ }^{18}$ que contiene datos sobre las sierras de Jaén en el siglo XIV. Ninguno de los topónimos que aquí figuran son del valle de Otínar, los que se pueden reconocer hoy (Madroñal, Rio Frio, Carchena, Navalengua, Bercho...) lo rodean por el oeste y el este. La causa podemos buscarla por un lado en la posibilidad de que estas tierras permanecieran bajo dominio granadino o como tierra de nadie desde que fueron perdidas durante el reinado de Sancho IV (1284-1295) (ALCÁZAR, 2003:234-235); por otro en que su deforestación fuera tal que no albergase interés cinegético alguno; o, finalmente, que, como defienden algunos autores (recogidos en MONTOYA, 1992: 16), el Libro de Monterías fuese redactado durante el reinado de Alfonso $X$ (1252-1284) en plena época de consolidación de la conquista de Jaén, en momentos por ello de despoblamiento rural y discontinuidad en la ocupación y explotación del espacio. La primera opción parece la más factible habida cuenta que la segunda supondría una degradación ambiental extrema, que no se ha producido ni tras la desecación del río Quiebrajano a finales del siglo $X X$, y la tercera supondría una doble toponimia castellana para el valle de Otíñar: una primera tras la conquista de Fernando III, presente en el Libro de Monterías y hoy perdida, y una segunda del siglo XIV tras arrebatárselo por segunda vez a los nazaríes que es la que, en parte, nos llega.

La vida del poblado castellano de Otínar abarcó posiblemente desde finales del siglo XIII hasta mediados del siglo XIV o del XV (en

\footnotetext{
17 En la batalla de las Navas de Tolosa Alfonso VIII contaba con las tropas del Señor de Vizcaya y del Rey de Navarra. Lope Díaz de Haro, Señor de Vizcaya con 500 hidalgos tomó Baeza en 1227 para Fernando III y la flota del Almirante de Castilla Ramón Bonifaz que participó en la toma de Sevilla por Fernando III estaba mayoritariamente formada por guipuzcoanos y vizcaínos. Sin embargo se desconoce la composición del ejército en la conquista de Jaén y se ha perdido el repartimiento de la ciudad, por lo que no se sabe a través de quién se establece el vínculo entre la Sierra Sur y Guipúzcoa-Navarra.

18 En esta fuente figuran nombres de lugares con valor cinegético pertenecientes a Jaén, Martos, Alcalá la Real y Cambil. Todos ellos rodean la actual Sierra de Jaén.
} 
I3II ya figura con parroquia ${ }^{19}$ y en 1508 ya está despoblado ${ }^{20}$ ). Localizado en el cerro del Castillo de Otiñar ${ }^{21}$ ocupa una extensión de aproximadamente 3 has (incluido el castillo) y desde él se explotaron las tierras del entorno donde todavía en el siglo XVI se distinguían "figueras y Tierras y Guertas y Morales e otros muchos árboles" (Real Cédula de la reina Doña Juana de 17 de marzo de 1508 en CAZABÁN, [1916] 1982:77). Entre la conquista de Jaén en I 246 y la conquista de Cambil en I 485 Otínar está en la frontera. La defensa de este sector de la frontera corresponde al concejo de Jaén, y podemos entender que la aldea se funda a instancias del mismo. Esta ocupación dotó lógicamente de referencias toponímicas al valle, pero de ellas sólo nos han llegado las transmitidas por los guerreros que mantuvieron en uso el castillo y habitaron el valle hasta el siglo $X V I I$, actuando como enlaces con los ganaderos con los que convivían y que les sucedieron.

La segunda fuente de interés son las Ordenanzas Municipales (PORRAS ARBOLEDAS, 1993) recopiladas en el siglo XVI, en ellas se cita 'Otinnar' en las ordenanzas IV y $\vee$ de la Dehesa del Concejo en las que para la protección del aprovisionamiento del castillo se prohiben talas en el valle y se otorga protección a los ganados de los arrendatarios de la dehesa. En esta fecha ( 1499) se aprecia ya el uso que se daba a estas tierras, que tras el abandono de la explotación agrícola, con la desaparición de la aldea castellana se convierte en la mayor de las posesiones de los propios de la ciudad de Jaén.

Pero es en los Hechos del Condestable donde se aprecia el valor militar del enclave. En I 464 el Codestable Iranzo manda que la alcaidía de Otínar se dote con 8000 maravedíes para mantener tres hombres y un alcaide y mil maravedíes para la caballería aneja de la Sierra (CUEVAS, DEL ARCO Y DEL ARCO, 200 I:172). Esta dotación es la mayor con diferencia de las 20 alcaldías y oficios que se repartían entre los caballeros de las distintas collaciones de la ciudad. Por ejemplo a Fuerte del Rey y Cazalilla correspondín 3000, a cada uno de los castillos de la ciudad, Torredelcampo, Berrueco y Mengibar 5000, al castillo de Pegalajar 7000. El castillo forma parte del sistema de defensa que despliegan la ciudad y los señoríos vecinos para asegurar las comunicaciones y las tierras, su eficacia defensiva y disuasoria depende del buen funcionamiento de ese sistema. El flanco sur sostenía la lucha más peligrosa y Pegalajar y especialmente Otíñar recibían mayor compensación. Entre I 465 y 1469 la principal preocupación de Miguel Lucas de Iranzo fue organizar la frontera y en los Hechos se menciona a que collación cae en suerte la alcaldía de cada castillo y aldea, entre ellos Otínar. Con posterioridad la ciudad mantiene la dotación del castillo de Otínar y en las fuentes se siguen datos dispersos al respecto como que en I47 I Gerónimo de Torres (elegido por la ciudad) sustituye como alcaide a Benito Sánchez de Madrigal (CAZABÁN 19|4:57), o que en 1499 el alcalde es Diego de la Chica (Porras Arboledas, 1993: I 4I). Aunque la importancia militar del sitio decae con la toma de Granada todavía en 1627 había nombrado un teniente de alcaide del castillo de Otíñar (CAZABÁN 1922:231).

Se comprende que topónimos como Castillo de Otínar, Peña de la Bríncola, Las Alcandoras, Cinta del Fraile, Fuente de los Ballesteros, la Escaleruhela sean del momento de la conquista bien por pertenecer al acerbo semántico de los guerreros como Castillo de Otíñar, Las Alcandoras (fuegos para señales), Cinta del Fraile (cinto = recinto amurallado), Fuente de los Ballesteros; bien porque figuran en las fuentes bajomedievales como Escaleruela, mencionada en la Ordenanza V de 1499, (Porras Arboledas, 1993:141); o bien porque provienen del

19 La primera mención del topónimo 'Otíñar' se recoge en documentación eclesiástica de |3| I, figurando junto al Alcázar como collación de la ciudad, sometida a la directa administración eclesiástica de su obispado (RODRÍGUEZ MOLINA, 1982:208).

20 El asentamiento medieval de Otínar es definido en 1508, cuando la reina Doña Juana intentó su repoblación como “...villa cercada de buen muro de cal e canto con una fortaleza, en la cual se podía hacer una villa de 50 vecinos..." (CAZABÁN, [1916] 1982: 78).

2I En Salvatierra (1995: |46-150) se encuentra una descripción del mismo. 
País Vasco y Navarra (Otínar, Bríncola, Peña Blanca, La Parrilla).

La frontera como expresión espacial de la guerra y la conquista domina ese universo semántico: el valle se entiende como un recinto cerrado defendido por los escarpes al este (la Cinta del Fraile) y por el bosque al oeste (la Matilla), con accesos vigilados (Collado de los Bastianes, Puerto de las Lagunillas, etc.) y un centro de control: el castillo. Desde él se domina la cuenca visual del valle, que coincide con el área de abastecimiento que tiene asignada como término. Todos los caminos llegan y parten del castillo que es un punto final hacia el sur: el borde de la frontera cultural y política. Mientras la aldea subsistió, el castillo defendía a los colonos, vigilaba los caminos y cuidaba los campos, formaba parte de un complejo social amplio donde, con los guerreros, estaban los campesinos y los frailes, completando la terna social feudal (los que labran, los que luchan, los que rezan). Cuando la aldea se despobló el castillo mantuvo su función de punto central de la defensa de la ciudad y siguió controlando los caminos y los pastos ${ }^{22}$. De la toponimia de los campesinos castellanos de la aldea medieval probablemente no se ha transmitido nada, porque quienes sirvieron de enlace, los guerreros $y$, en menor medida, los ganaderos la excluyeron del nuevo discurso ${ }^{23}$ que atendía a líneas de tránsito y defensa. Tampoco queda mucho del universo de los que rezan: el topónimo La Iglesia, referido a una estructura rectangular ubicada frente al castillo y el paraje del Fraile que concentra la Cinta del Fraile, la Nariz del Fraile, el Portillo del Fraile y el Peñón del Fraile ${ }^{24}$.
Por ello sólo podemos rastrear los nombres de lugar que imponen y transmiten los conquistadores. Estos fueron elegidos siguiendo la forma dominante del saber precientífico que, para Foucault ([1966] 1999: cap. II), es la Semejanza: el escarpe es la muralla (Cinta del Fraile), la Brinkola vasca es la Bríncola de Otíñar, el paso excavado en la roca parece una escalera (la Escaleruela) ${ }^{25}$. En este modo de representar el paisaje lo más interesante es que la semejanza establece, mediante un mecanismo de emulación, una simetría entre una imagen conocida (Navarra-Guipúzcoa) y un reflejo (Otínar). El eje sobre el que pivota esta simetría no es geográfico sino simbólico: el recuerdo se hace vínculo, y crea un paralelismo inmediato en el tiempo no en el espacio. Pero el reconocimiento de semejanzas no se detiene en la mera especulación intelectual (el saber) sino que sirve para convertir un espacio ajeno en un paisaje propio, bautizándolo, es por ello un símbolo de la apropiación (el poder). En esta tarea el guerrero no está solo, le acompaña el cura, que lo alienta y protege, pero cuya tarea principal es adoctrinar a los aldeanos y que, por ello desaparece cuando la aldea se abandona. De este modo la cultura castellana, cristiana y feudal, decide que es dominante, que es marginal y que es excluido del discurso que se hereda.

\subsubsection{El paisaje de los pastores}

Hacia mediados del siglo XV con la aldea ya despoblada, la ganadería, aunque puntualmente estorbada por las razzias, se erige en la actividad dominante en el valle. Es de suponer que la corona otorgara a la ciudad de Jaén el dominio sobre el valle de Otínar, lo que

\footnotetext{
22 A la jurisdicción del alcaide del castillo cabe sancionar a los propios ciudadanos de Jaén que, sin derecho, entren ganado en el valle (PORRAS ARBOLEDAS, 1993: 141).

23 El único rastro de aquellos pobladores lo encontramos disperso en algunos de sus descendientes que llevan el topónimo 'Otínar' como apellido. Según el Instituto Nacional de Estadística en 200 I había censados 62 personas con este apellido (30 de primero y 32 de segundo), de ellos el $89 \%$ residen en la provincia de Jaén.

24 Existe un Puntal del Púlpito en el Barranco de la Tinaja que parece deber su nombre a su forma y que por ello podría adscribirse tanto a la Otínar medieval como a la contemporánea. Por otra parte los nombres de lugar que contienen la palabra Fraile pueden referirse asimismo a un ermitaño que ocupó tierras en Otíñar y que fue expulsado por el Ayuntamiento en I570 (CORONAS, 1994:331).

25 Gómez Ortín (1977) descarta esta etimología y propone un origen prerromano para el topónimo Escarigüela o Carrigüela del que Escaleruela sería una ultracorrección. Sin embargo se equivoca puesto que en Otíñar la variante Carrigüela presente en la etimología popular es posterior (s. XIX) y derivada de Escaleruela (s. XV).
} 
explica que dependiera de ella su aldea, que casi con seguridad sería una colonización ordenada por el Concejo. Cuando el experimento repoblador fracasa, la ciudad recupera para sus propios el término de la aldea y lo adscribe al Castillo de Otiñar. Otínar se convierten así en dehesa y el Concejo saca a subasta sus pastos y aprovechamientos forestales. Carboneros, neveros, leñadores, cazadores y recolectores de toda laya arrendaban la riqueza de estos montes. Ahí quedan el Barranco de los Neveros y la Pasada de los Carboneros como evidencias sobre el terreno. Pero son los pastores los verdaderos beneficiados por la oligarquía municipal que controlaba los arriendos de los pastos, y cuyos intereses eran puntillosamente guardados por la Mesta local de Jaén (CORONAS, 1994: 340) aglutinada en torno a la poderosa Cofradía de Santo Domingo de los Pastores.

Durante los siglos XIV y sobre todo XV y $X V I$, en plena efervescencia colonizadora, la cofradía pleiteó contra la reducción de las tierras de pasto que suponían los nuevos cultivos (QUESADA, 1994: 18, nota 7; RODRÍGUEZ MOLINA, 1985: 123-127); contra la concesión de nuevas dehesas a los cortijos (QUESADA, 1994: 19, nota 8), que reducían los pastos comunes y arrendables; y contra la ocupación de las cañadas, veredas, descansaderos y abrevaderos (CORONAS, 1994: 331) que impedía el tránsito del ganado. Pese a ello el proceso de particularización de la tierra, del que esta lucha entre agricultores y ganaderos es un episodio, era imparable y a finales del XV la mayor parte de las tierras para pastos van quedando relegadas a la Sierra, en los propios de la ciudad. De ahí que cuando se inicia la repoblación de la Sierra Sur esta es contestada con fuerza por los pastores que consiguen primero que los términos de las nuevas poblaciones sean de uso común con el de Jaén, lo que les otorgaba derechos sobre los mismos; y segundo que de las siete aldeas con 800 vecinos que la reina Doña Juana ordenó fundar en 1508, sólo se empiecen a cons- truir cuatro en 1539, entre las que no se cuenta Otínar, que es la más cercana a la ciudad.

De este modo Otíñar y La Parrilla pasan a ser dos cuartos más de los quince en que, con el tiempo, se dividen los propios de la ciudad en la Sierra (LÓPEZ CORDERO, 1998: 215). El propio término 'cuarto' hace referencia a "cada una de las suertes, aunque no sean cuatro, en que se divide una gran extensión de terreno para vender los pastos" (Diccionario de la Real Academia, 1992). Esta denominación nos sitúa en una tierra ganadera que es la que describen las ordenanzas de la ciudad ya en el siglo $X V$ y que se mantendrá hasta su enajenación en 1827.

Precisamente en la escritura de venta ${ }^{26}$ que certifica, en marzo de 1827, la desamortización de estos valles, se encuentra un conjunto de nombres de lugar que atañen al deslinde y a los posibles aprovechamientos. Destacan la predominancia de topónimos relacionados con accesos y recursos hídricos y la práctica ausencia de nombres propios de lugares agrícolas. Veredas, collados, puertos, fuentes y nacimientos son los focos de interés, lo que se comprende porque sus objetivos son por un lado delimitar la nueva propiedad y por otro establecer un justiprecio en función de sus capacidades productivas. Sin embargo y pese a que se aprecian y mencionan vestigios de antiguas huertas a estas no pueden darles nombres propios puesto que se desconocen, sin embargo las fuentes, manantiales y pasos se listan con precisión, esto puede deberse a que la información proviene de quienes mantenían en uso estos recursos, de aquellos que aprehendían este paisaje como tierra para pastos.

La Parrilla y Otínar se mantienen como dehesa de yeguas al menos hasta finales del siglo XVIII (MARTíNEZ DE MAZAS [1794] 1978:393; LÓPEZ CORDERO, 1998: 125-126), no obstante la entrada de rebaños de ovejas, cabras y vacas en la dehesa sería constante como muestra la

26 Archivo Histórico Provincial, Legajo 2356 
ordenanza IV de las dehesas de la ciudad que en 1499 ya fijaba multas para los ganaderos que entrasen cabras, ovejas, cerdos, yeguas o bueyes, señalando que tales penas ya eran antiguas y estableciendo que el monto de las mismas fuese para los arrendadores (PORRAS, 1993: 14I). El arriendo como modalidad de explotación contemplaba la subasta del pasto y de las hojas de los árboles, porque para su reproducción y mantenimiento la dehesa precisa de la existencia de amplias arboledas que permitan el abrigo del ganado, el abastecimiento de hojas y frutos y la perduración de las hierbas. El adehesamiento afectaba a las zonas más a propósito para los distintos tipos de ganados, primero a las vegas donde podían pastar las yeguas, los bueyes y las ovejas, que eran zonas llanas, libres de estorbos y con arboledas (soto del Quiebrajano, frutales abandonados, lindes arboladas...), después la mayor parte de las laderas margosas con pendientes más o menos acusadas y los poyos de los escarpes, donde la cabaña caprina y, en ciertos lugares también la ovina, encontraban alimento.

De este modo durante casi 500 años la actividad ganadera se adueñó del valle dejando una fuerte impronta tanto por su incidencia sobre el paisaje como por su papel en la transmisión de una determinada imagen de esta tierra a los colonos del siglo XIX. Un rasgo definitorio de esta ocupación es que no se trata de una comunidad pastoril con un asentamiento permanente en Otíñar sino de una explotación temporal mediante arriendos de diversa duración regulados desde la ciudad. Por tanto el derecho de pasto lo otorgaba la oligarquía giennense que cobraba la renta y vigilaba el cumplimiento de los contratos. Aunque no se trata de ganadería trashumante sino estante o, a lo sumo, riveriega, el arriendo situaba a los ganaderos en una especie de paisaje dinámico, sin casa estable y sin certeza en la continuidad. El pastoreo extensivo con grandes rebaños 27 de propietarios absentistas remite a un grupo de pastores muy jerarquizado, seleccionado por criterios de capacidad o conocimiento y no necesariamente familiares, posiblemente un mundo predominantemente masculino en movimiento constante. Su trabajo comprendía, además de la conducción y vigilancia de los rebaños, la construcción y mantenimiento de majadas, cobijos y abrevaderos, el suministro de alimentación complementaria, la gestión de la producción tanto cárnica (castraciones, apareamientos, partos, venta de crías) como láctea (ordeño, venta de leche, queso), el herrado y defensa de los animales frente a robos y lobos, el adiestramiento, dirección y cuidado de los perros pastores, etc.

Como legado dejaron un conocimiento exacto de los recursos pecuarios que, en el espacio, se materializa en un sistema dependiente de tres componentes: alimento, agua y cobijo, articulados por una completa red de comunicaciones. El alimento se concentraba principalmente en las vegas y en las áreas de monte bajo (falda de la Matilla, Las Alcandoras, etc.); el agua en los remansos del Quiebrajano y en las fuentes (se conocen I5); y el cobijo en las majadas, de las que se conservan nueve (siendo las principales la Majada de los Carneros y la del Hoyón). Las huellas de esta ocupación que se funden con las del pastoreo de los habitantes de la aldea del siglo XIX, nos muestran espacios despejados rodeados de majanos (El Hoyón, El Corralón) o vegetación espesa (Majada de los Carneros), rediles de formas redondeadas construidos con calizas (Puerto de las Lagunillas, Collado de los Bastianes), abrevaderos (El Covarrón, Barranco de la Hoya), senderos y abrigos marcados por el humo. Son espacios ocupados de manera recurrente puesto que el ganado se encuentra dentro de un circuito cerrado en movimiento constante obediente a diversos ciclos (diarios, estacionales...).

\footnotetext{
27 En los expedientes de subasta de arriendos (Archivo Histórico Municipal: legajo 196) se especifica que en 1826 se alimentaron con los pastos y hojas de la Parrilla a 530 cabras, 250 ovejas y 30 vacas, mientras que en las vegas y Castillo de Otínar pastaron I. 100 cabras y 50 vacas. En total 1630 cabras, 250 ovejas y 80 vacas.
} 
El pastor no percibe el paisaje desde un centro como hace el guerrero en el castillo o el campesino en la aldea, sino desde los caminos. Sin embargo no es una percepción realmente nómada, donde la incertidumbre de un espacio desconocido o de un tiempo nuevo en un lugar familiar hace extraña a la tierra y errático el viaje, sino itinerante con destinos prefijados y acostumbrados, con tiempos y espacios cíclicos. Ese paisaje descentrado, periferia espacial y social, es un lugar que el pastor no domina porque primero el castillo y después la ciudad se lo impiden. No obstante necesita apropiarse el paisaje para usarlo, y crea un mundo en movimiento, cíclico, pero a diferencia del agricultor el ciclo además de temporal es espacial. Ese paisaje cíclico está dominado por los recorridos: del pasto a la sal, de esta al agua, después a la majada y vuelta a empezar, pero también y de manera obsesiva por los límites. El arriendo afecta a una tierra marcada en el mejor de los casos por hitos muy dispersos, que son presencias dominantes en un mundo donde primero la Caballería de la Sierra y después la Guardia Civil y la Guardería Forestal vigilaban que los rebaños no pasaran a los otros cuartos o a los montes públicos. Los pastores tenían esto muy presente y debían conocer los límites exactos de su dehesa. En cierto modo el paisaje se presenta como un redil, un espacio marcado por la cerca donde se permite que el ganado se mueva bajo un control exterior: el del pastor ${ }^{28}$.

Nos encontramos con que el paisaje ganadero es un lugar sin centro, con perímetro muy marcado y cruzado por un sinfín de caminos, por tanto es un mundo de líneas de tránsito. Este viario es un sistema topológico complejo donde caben tramos en retícula y tramos en árbol, lo que nos sitúa en un espacio ordena- do en parte desde arriba, que es decir desde fuera (árbol), y en parte desde abajo o desde dentro (red). El eje vertebrador de la tierra de la ciudad de Jaén en la Sierra era el camino de Jaén al Castillo de Otínar ${ }^{29}$ que, por su posición central entre las posesiones de la Sierra, responde a las necesidades de comunicación entre los valles del sur, que durante el siglo XVI irán consiguiendo su independencia jurisdiccional: desde el Castillo se puede ir a Jaén (al norte), a Puerto Alto y La Guardia (al noreste), a la Cañada de las Azadillas y Los Cárcheles (al este), al Valle del Parrizoso y Campillo de Arenas (al sur), al valle de Valdepeñas (al suroeste) y al valle de Los Villares (al oeste). Esta estructura en árbol establecida por necesidades de comunicación exterior de la ciudad se completaba con una estructura en red que saliendo de cada uno de estos caminos permitía acceder a todos los puntos de cobijo y abastecimiento dentro del valle, entrelazando los parajes en una densa trama de recorridos ${ }^{30}$.

Este universo pastoril de dilatada duración presentaba debilidades que lo hacían debatirse en equilibrio inestable. Primero la presión sobre el medio mediante quemas (LÓPEZ CORDERO, 1998: 127) y talas hacía menguar su capacidad de recuperación; segundo el uso al que estaba destinado era sistemáticamente sobrepasado y desde el siglo XVII son frecuentes las órdenes de la corona para remediar la caída de la cría caballar por el perjuicio causado al ejército; tercero la presión de los agricultores sobre las dehesas de la Sierra fue constante y se conocen usurpaciones de tierras para viñas en los alrededores de Otíñar (Peña de la Bríncola) en 1526, y en el camino de la Parrilla (LÓPEZ CORDERO, 1998: 109-110), y consta que en 1570 el Concejo acusó a un ermitaño de ocupar tierra en la Fuente de la Olivilla, localizada al sur del

28 Si se dispusiera de información más exhaustiva anterior al siglo XIX se podría comprobar si la semejanza vuelve a emerger como el proceso mental que ordena la representación: el cuarto de Otínar sería un gigantesco redil, con las crestas del valle como empalizada que señala su límite y el castillo o la ciudad (según el momento) como pastor.

29 Ese camino fue reparado en tiempos de Carlos III como atestigua el monolito conmemorativo situado en la ladera de Cerro Veleta, denominado con propiedad El Vítor.

30 Sin embargo en los cuartos de Otíñar y La Parrilla no existían veredas reales, la más cercana era la Cañada Real de Los Villares a La Guardia que servía de lindero norte al cuarto de La Parrilla, esto se debía a que el término de Jaén estaba exento de cañadas mesteñas, ya que, por ser tierra fronteriza, sólo tenía dehesas concedidas por el Rey (CORONAS, 1994: 330). 
Castillo de Otínar, habiendo construido y plantado en la misma (CORONAS, 1994:331). Todo ello prefiguraba el verdadero cambio que no se produce hasta que, con su desamortización en I827, se provoca la construcción de la aldea de Santa Cristina, que supone una nueva campesinización del paisaje ${ }^{3 !}$.

\subsubsection{El paisaje de los campesinos}

La construcción de la aldea de Santa Cristina impone al paisaje un nuevo orden, dominado por las exigencias productivas de una comunidad estable en expansión y una propiedad con fuertes ambiciones, que lo somete a una presión constante y creciente. Imagen y fruto de esta presión que se mantiene durante 150 años es la densa trama de topónimos que cubre al paisaje. Como se ha dicho en ese conjunto de nombres de lugar transmitido por la $5^{\mathrm{a}}$ generación de pobladores de Santa Cristina caben (degenerados, reestructurados, desintegrados...) parte de los discursos preexistentes: el de los ganaderos que explotaron la dehesa de los propios entre los siglos XV y XIX y el de la aldea medieval cristiana, que han perdurado fragmentados para dejar lugar a las nuevas representaciones. Este proceso deposita capas de significado sobre el paisaje, que después son filtradas, reinterpretadas, completadas y transmitidas a través de la mentalidad y los conceptos de unos campesinos del siglo XIX, que construyen un nuevo discurso.

La estructura del nuevo discurso toponímico está directamente relacionada con la representación mental que del espacio se hacían en la aldea campesina. En esencia está dominado por dos ideas-fuerza: por un lado la contraposición nosotros-ellos con su materialización espacial dentro-fuera, y por otro la semejanza como expresión de la forma de conocimiento dominante, organizadora de los símbolos y directora de la representación. Este discurso se concreta en dos conceptos espaciales que se interconectan: el de escala que contiene la contraposición dentro-fuera y el de simetría que expresa las relaciones de semejanza.

La contraposición nosotros-ellos es básica en la autoafirmación de la comunidad y por ello está presente desde que esta existe. Hasta la segunda generación Otíñar, comunidad de origen colonial ${ }^{32}$, no está en disposición de afirmarse como tal, frente a otras y frente al terrateniente. Ya se ha referido cómo al poder del amo oponen en ocasiones resistencias palpables pero siempre resistencias simbólicas, y se ha de añadir ahora que la primera oposición es que ellos son otiñeros y los amos no, porque aunque hubieran nacido allí, no forman parte de la comunidad: no son de Otíñar, Otíñar es de ellos. Por tanto la autoafirmación como comunidad se encuentra vinculada al nombre propio de lugar, que es el nombre del pueblo, concepto que en español se refiere tanto a la localidad como a la comunidad que la habita (PITT-RIVERS, 1971:19) ${ }^{33}$. Esta asociación entre la comunidad y su paisaje explica que la contraposición nosotros-ellos sea tanto social como espacial (dentro-fuera), haciendo residir la identidad en el lugar que se habita. Castell (1998: 28) entiende por identidad "el proceso de construcción del sentido atendiendo a un atri-

\footnotetext{
31 Las menciones en archivos y Ordenanzas (PORRAS, 1993:197) a la Huerta de Otínar o al Pago de Otínar (MARTíNEZ DE MAZAS, JOSÉ ([1794] 1978):364, nota a), donde, desde el siglo XVI, arrendaban tierras tanto la Mesa Capitular de la Catedral (CORONAS, 1994: 258), como otras instituciones (A.H.D.P.J. Leg. 2133//3) o particulares (A.H.D.P...: Leg. 2194/4I) se refieren a una zona situada fuera del Cuarto del Castillo de Otíñar, y que, según el censo de 1818, ocupaba una extensión de 82.9 cuerdas (LÓPEZ CORDERO, 1998: 186). Por otra parte se atribuye al Sitio de Otíñar la finca colindante de la Vereda porque pertenecía al mismo latifundio (codicilo de Jacinto Cañada de 28/I2/I844, A.H.P.J. Leg. |476), habiendo sido antes del siglo XIX y hoy topónimo independiente. Esto viene a demostrar el poder del valle de Otíñar como referencia, y no que existiesen tierras cultivadas en el mismo durante los siglos XVI, XVII y XVIII.

32 Existe un topónimo revelador del carácter colonial: 'chiripa', refiriéndose a suerte de tierra en la vega. Expresión con el mismo significado que 'suerte' que si hacemos caso al D.R.A.E. de 1739 proviene de la costumbre de repartir la tierra por suerte (se entiende que en los procesos de colonización), que en Otínar se toma al pie de la letra hablando no de la suerte de tierra de mengano, sino de la Chiripa de tal, que es un sinónimo popular de azar o suerte.

33 Son conocidas las reticencias que en la literatura antropológica española levantan el concepto de 'comunidad' (MORENO, 1972), sin embargo en este caso su uso está justificado por no tratarse de un estudio de comunidad a la manera de la antropología anglosajona sino de un estudio histórico en el que no se priman los aspectos cohesivos e integradores sobre los disolutivos y conflictivos.
} 
buto cultural, o un conjunto relacionado de atributos culturales, al que se da prioridad sobre el resto de las fuentes de sentido", de manera que en las comunidades campesinas fuertemente homogeneizadas del Alto Guadalquivir, la búsqueda de la diferencia con las comarcanas no se puede establecer en función de las distintas formas de articulación social, como podría darse si se comparasen con otros espacio (v.g. el Cantábrico) u otros tiempos (por ejemplo las aldeas islámicas del otro lado de la frontera medieval), sino atendiendo al paisaje, que quizás sea el único atributo cultural que, en la Sierra Sur de Jaén en el siglo XIX, permite a una determinada comunidad campesina diferenciarse de otra vecina.

El vínculo entre paisaje e identidad comunitaria lleva directamente al concepto antropológico de 'lugar' como ámbito donde se expresan y son reconocibles la identidad, las relaciones y la historia de quienes lo ocupan (AUGÉ, 1992). Concepto dependiente del contexto en que se manifiesta, lo que permite reconocer como 'lugar' la casa, la aldea, la ciudad, la región, la nación, etc. múltiples espacios donde a escalas diferentes se crean identidades y se establecen relaciones, que son, en definitiva, el marco activo de la historia de sus habitantes ${ }^{34}$. Esta noción de lugar es compartida por la comunidad campesina de Otínar que representa su espacio como un hábitat permanente, con unos límites fijos, en cuyo interior se localizan un conjunto de parajes, que contienen a su vez grupos espacialmente significativos de superficies irregulares, que pueden asimismo estar subdivididas, conectados por redes de comunicación (visual, circulatoria, sonora). Todos esos lugares tienen nombre propio, y su gran número evi- dencia la necesidad de los sucesivos planos de acercamiento a la realidad que se precisan para aprehenderla. Estudios recientes han demostrado que el número de topónimos que un ser humano puede dominar no llega a los 500 (HUNN, 1994), por lo que hemos de disponer de un mecanismo de criba que nos permita referirnos con la suficiente elasticidad a muy diversos territorios: países, paisajes, parajes, puntos... A esta necesidad nuestra cultura responde con una aproximación escalar que en Otínar obedece al esquema dibujado en la figura 7.

La asociación entre los nombres de lugar a distintas escalas (nombre del municipio: Jaén, nombre de la aldea: Otínar, nombre del cerro: Bríncola) depende de factores históricos diversos como su apropiación cultural o su situación en el sistema de poderes, valores y usos de la comunidad. Por ello los topónimos que se relacionan a distinta escala no admiten un discurso narrativo o conceptual. En la articulación de escalas toponímicas no encontramos un discurso coherente sino un conjunto de elementos con sentido (los paradigmas de los semiólogos) en los que domina una relación no discursiva sino, en este caso, espacial ${ }^{35}$. El cluster que representa esta relación contiene en la lectura horizontal de cada nivel un discurso sintagmático (coherente, con significado), de manera que al pretender abarcar la totalidad de la realidad originan múltiples asociaciones. Así Otíñar, desde fuera es abarcada por un sólo nombre de lugar o su sinónimo (Otíñar o Santa Cristina); en sus diversas escalas interiores (paraje, parcela, punto) contiene entre diez (parajes) y cincuenta (casas) nombres en los que es posible descubrir relaciones y regularidades significativas $^{36}$.

\footnotetext{
34 El diccionario de la Real Academia Española de la Lengua fija como primera acepción de 'lugar' en I734 y hasta I 803 la de "espacio que contiene en sí otra cosa", la Academia recoge, no inventa, esta "naturalización" de las relaciones escalares: el lugar como contenedor de contenedores.

35 La distinción convencional entre toponimia mayor y microtoponimia no sirve para acercarnos a la realidad del paisaje pues aunque denota un conocimiento intuitivo de la escalaridad de los nombres de lugar, no penetra en sus sutilezas y no permite una reconstrucción de la compleja jerarquía de los espacios.

36 La toponimia se revela como un sistema de significados en el que podemos utilizar la distinción semiótica entre sintagmas (discursos con sentido horizontales y combinatorios) y paradigmas (conjunto virtual de elementos de una misma clase gramatical, que pueden aparecer en un mismo contexto). El primero nos introduce en el universo de relaciones evidentes entre la comunidad y su tierra, el segundo nos traslada a un nivel más profundo intentado llegar a conocer las causas históricas que explican la presencia de un nombre concreto y no otro. Por tanto este sistema dispone de una estructura escalar y sintagmática que ordena las relaciones que lo rigen sometida a un proceso evolutivo estratigráfico y paradigmático.
} 
La casa como expresión espacial de la familia y la aldea como la de la comunidad son las manifestaciones más evidentes de la contraposición nosotros-ellos a distintas escalas. Este carácter de la casa (unidad de parentesco, de producción y de residencia) explica el uso de topónimos que expresan posesión (la casa de, la huerta de, las olivas de), que separan el universo familiar del resto. En cuanto a la aldea a la que hay que entender como paisaje apropiado, como término y no como grupo de casas, se ha comentado la insistencia en destacar los límites con topónimos que significan o bien no-controlado (Lobos, Corzos, Víbora...) o bien frontera o barrera (Frontón, Cinta, Mata, Reventones...) marcando la separación con otros ámbitos. Otras contraposiciones presentes e incluso dominantes que tienen una lectura espacial, como la de hombre-mujer, sin embargo no se han sabido o podido reconocer en la toponimia, de manera que espacios de socialización femenina, por ejemplo el Lavadero, como comparte otros usos (abrevadero), sólo entre mujeres recibe este nombre, siendo el dominante Fuente de la Cañada. No obstante la mujer participa de la apropiación, habiendo casas, huertas y olivas con su nombre, lo que indica que la unidad familiar puede estar a su cargo y que mantiene una intervención activa en la explotación de la tierra ${ }^{37}$.

La casa y la aldea como elementos conformadores del modo de vida campesino también son aprehendidos a través de la otra ideafuerza: la semejanza. Ya se comentó como en el medievo la semejanza podía explicar la presencia de topónimos guipuzcoanos y navarros en la Sierra Sur, estableciendo una asociación entre un mundo de origen y un reflejo donde este se vería recordado por voluntad de los conquistadores. Esta asociación se establece por emulación ${ }^{38}$, por el deseo de imitar (recrear) una tierra lejana pero, de una u otra manera, propia. No es esta la vía por la que la semejanza domina las representaciones de la colonia decimonónica, sino la de la contigüidad o conveniencia, que es una semejanza "ligada al espacio en su forma de cerca y más cerca" (FOUCAULT, [1966] 1999: 27), y que "por el encadenamiento de la semejanza y del espacio, por la fuerza de esta conveniencia que avecina lo semejante y asimila lo cercano, el mundo forma una cadena consigo mismo" (FOUCAULT, [1966] 1999: 27). De esta manera la semejanza domina tanto la conexión de los distintos lugares entre sí como la relaciones espaciales a distinta escala. Se trata de un juego de correspondencias que trama al espacio con simetrías horizontales y verticales.

El eje de las simetrías horizontales lo fija el punto de vista dominante, el que desde el pueblo se dirige al escarpe de la Cinta del Fraile, y siendo más concretos desde el Peñón del Mirador (donde, como indica su nombre, se controla todo el valle) al Peñón del Fraile (que marca el mediodía cuando le da el sol ${ }^{39}$ ). En el lado norte de este eje se dispone Cerro Veleta y Cerro del Calar y más al norte y unido este último el Cerro del Calarillo, en el sur Cerro Veleta del Covarrón y Cerro Calar del Covarrón y más al sur junto a este el Cerro de la Calarilla. Dos formaciones paralelas de orientación suroeste-noreste que en su contacto con el Cerro de la Mata, límite occidental del valle, forman un espacio en $U$ que abraza al poblado, quedando este en un ámbito abierto al este y protegido al sur, norte y oeste. Esta localización no hay que atribuirla a una geomancia, exceso de sentido que ya ha sido convenientemente criticado (CRIADO, 1999: 55), sino literalmente a una geo-sofía, nada esotérico o metafísico sino eminentemente práctico: el conocimiento del potencial, las bondades y los peligros de la tierra cruzado con el conocimiento de las necesidades, las técnicas y las capacidades de la comunidad. En el caso de la

\footnotetext{
37 En lo que respecta a la toponimia como en todos los campos del saber el conocimiento no es homogéneo, sino que fluctúa dependiendo de la posición de clase y estatus de cada grupo en la sociedad.

38 Aemulatio: una de las cuatro formas de la similitud, una especie de conveniencia (contigüidad) no ligada al espacio y que actúa en la distancia (FOUCAULT [1966] 1999: 28).

39 Lugar al que se vuelven con frecuencia todas las miradas para saber la hora ya que su sombra señalaba el mediodía y con él la pausa para el almuerzo.
} 
ubicación del poblado la opinión del primer barón fue decisiva, y en ella pesaron la cercanía a las fuentes de agua, al camino y a las tierras de cultivo y también se consideró, según la escritura de venta, que presentaba "una vista agradable y ventajosa" (Archivo Histórico Provincial. Leg. 2356). Como se ve estos conocimientos no se reducen a tecnologías o procesos de trabajo abarcando también gustos, intuiciones o lugares comunes. En cualquier caso el poblado se funda con la función de instituirse como centro geográfico y simbólico de la comunidad y esta, en su imaginario, lo asume otorgándole la posición central en una orografía simétrica.

Posición que también ocupa en la simetría vertical que a diferencia de la horizontal no se establece a partir de un eje de visibilidad sino por la proyección del centro simbólico que recorre los dos planos de socialización: la casa y la aldea. La casa campesina se entiende como un complejo social y espacialmente significativo formado por una unidad de parentesco, de producción y de residencia, la idea que la sustenta y los medios materiales necesarios para su reproducción: edificios, fondo común, tierra y ganado. Por su parte la aldea es un complejo social y espacialmente significativo formado por una comunidad de unidades domésticas vinculadas por relaciones de vecindad, producción y reproducción que comparten paisaje y modo de vida. La simetría vertical, interescalar, utiliza como eje la línea que une el centro de ambos complejos: el centro de la casa (la residencia) con el centro de la aldea (el poblado), y en su torno se establecen un conjunto de paralelismos. La semejanza entre la casa y la aldea no se revela en la similitud de denominaciones, sino en sus significados y usos paralelos. La sala es la plaza, lugar de reunión de la familia y de la comunidad, espacio principal también abierto a los de fuera; el pasillo es la calle, comunica el exterior (calle o campo) con el interior (sala o aldea); la puerta es el puerto, umbral que une y separa lo interior de lo exterior; el corral es el ejido, espacio productivo de uso múltiple donde la familia o la comunidad cuida ganado o se ocupa de su cosecha; la huerta es la vega, espacio productivo por excelencia, y fuente del sustento principal de las familias y de la comunidad; los muros de la casa y las lindes de la huerta son los confines del término, barreras de eficacia simbólicas, que marcan los límites de la apropiación familiar o comunitaria. Esta simetría es la mejor imagen de que el paisaje, para el campesino, es un espacio construido, igual que la casa, un lugar con el que se relaciona principalmente a través del trabajo ${ }^{40}$. Esto es así porque al derecho a la tierra del arrendatario se le pone como condición que rompa el monte y lo cultive, poniendo en práctica una de las principales reglas de la apropiación: la que exige transformar el lugar (MOLES Y ROHMER, [1972] 1990: 209).

Todas estas asociaciones son expresiones parciales de la simetría social entre la familia y la comunidad, que en este caso responde tanto a un vínculo simbólico (la voluntad de integrarse) como, dadas las prácticas endogámicas, a una realidad consanguínea. Es en este paralelismo social donde nacen y se funden la identidad y la semejanza; donde los mecanismos de explicación espacial de la escala y la simetría confluyen en un discurso coherente que permite la apropiación. Para los colonos campesinos la apropiación de su paisaje pasa por comprenderlo como un todo, señalando las cualidades de los puntos y parajes y diferenciando lo bueno de lo malo, lo interior de lo exterior, lo propio de lo extraño. Para ellos conocer es relacionar, de modo que asociar lo particular con los antropónimos, los límites del paisaje con barreras y esfuerzos o los peligros de la montaña con la maleza y las alimañas forma parte de su sistema de conocimiento que, aunque ajeno a la ciencia, sirve para disponer a cada cual en su sitio, aportando las normas y reglas necesarias para vivir en comunidad sin riesgos económicos, sociales o simbólicos. Este modo de representación del mundo ilustra sobre

40 Esto casa bien con la observación de Víctor Manuel Toledo (inédito, en ACOSTA, 2000:20) de que para el conocimiento campesino las unidades ambientales son unidades de manejo. 
cómo, dotando de significado a los lugares, se accede a un saber que es el instrumento que organiza y naturaliza su modo de vida y que, por tanto, sienta las bases sobre las que se ejerce el poder. En esta representación subyace el discurso que se convierte en el contexto donde se desarrolla la vida y el trabajo. Cuando la aldea se despuebla el contexto se desarticula y el discurso, relegado a la memoria de los ausentes, pierde su sentido. Sin embargo el paisaje permanece y sobre él caen nuevas formas de apropiación implantadas por un sistema en el que a las nuevas funciones les corresponden nuevos símbolos.

\section{NUEVO SISTEMA, NUEVAS FUNCIONES, NUEVOS SÍMBOLOS: EL PAISAJE ESPORÁDICO}

\author{
Sin entrañas y sin voz la tierra es, enton- \\ ces, pura epidermis, superficie sobre la que se \\ deslizan torpemente nuestros sentidos.
}

Rafael Argullol, Ver el alma de las cosas

Durante el proceso que se ha descrito algunos topónimos aun manteniéndose han variado: la Escaleruela (PORRAS, 1993: 141) pasó a la Carrigüela (fuente oral); el Arroyo de las Zarzaillas (MARTÍNEZ DE MAZAS, [1794] 1978) al actual Arroyo de las Azadillas (fuente oral); otros cambiaron y después fueron sustituidos: Candelebrax (PORRAS, 1993: 26I) devino en Candelebrage (MARTÍNEZ DE MAZAS, [1794] 1978: 362; MADOZ, [1845-50] 1988: 99) y después al actual Quiebrajano (cartografía oficial) ${ }^{41}$, pero estas fueron transformaciones puntuales que no denotan un cambio de discurso. No es hasta el nuevo despoblamiento de la aldea de Santa Cristina cuando se produce un verdadero proceso de sustitución. El cambio de nombre de Aldea de Otínar a Hacienda Santa Cristina que se impone tras la Guerra Civil es el complemento retórico que acompaña a las medidas adoptadas por el propietario para destruir la comunidad campesina, un estorbo anacrónico en la capitalización de la propiedad, que ahora se orienta a la producción industrializada. Con la desposesión de los descendientes de los colonos, desaparece la memoria de los nombres de sus lugares y también desaparecen sus lugares. En efecto paralelamente a la desposesión de los arrendatarios la propiedad lleva a cabo un proceso de reordenación del regadío para transformar las huertas campesinas en cultivos industriales, principalmente alfalfa, y esto implica la eliminación de meandros, linderos y terrazas en las vegas altas y con ellos la razón de ser de los nombres que definían estos espacios. Además los frutales que separan las huertas, especialmente las nogueras, son cortados desdibujando el parcelario campesino. El hecho de que se mantenga en explotación hasta la actualidad sin interrupción no ha evitado que el conocimiento del nombre de los lugares haya dejado de ser patrimonio de un pueblo, para convertirse en nostalgia de emigrantes. Por eso quienes hoy, de un modo u otro, se apropian de este paisaje se encuentran casi sobre una tabula rasa. Una tierra sin los límites y sin la memoria de quienes la construyeron es más fácil de reordenar, es una página en blanco sobre la que escribir un nuevo discurso. La metáfora es pertinente: para Pierre Lévy (1989: 163) la página es "el pagus en latín, el campo, el territorio cercado por el blanco de los márgenes, arado de líneas".

Pero no sólo los renovados intereses económicos de los propietarios alteran, desdibujan o borran el sistema simbólico campesino, sino que los otros nuevos apropiadores también dejan su huella, bien de un modo disperso, como los montañeros, o de un modo sistemático, como los ingenieros del catastro que con su meta-toponimia alfanumérica han inventado una forma metódica de recreación abstracta de la realidad. Al margen del conocimiento más o menos preciso que de la toponimia tengan el encargado de la dirección

\footnotetext{
4I Posiblemente de 'Quiebra' que en el DRAE es "hendedura o abertura de la tierra en los montes o la que causa el exceso de lluvia en los valles". Esta acepción cuadra a un río encajonado como este que sería el río de la quiebra o más usualmente río de la quebrada, o, en este caso, río quiebra-ano (ano = sufijo que denota procedencia, pertenencia o adscripción).
} 
de las tareas agrícolas y los propietario de la finca, que por la escasez e infrecuencia de sus contactos no tiene proyección externa ${ }^{42}$, son los visitantes esporádicos los que, desde los años 70 del siglo $X X$, están renombrando las tierras de Otínar. Hay visitantes para los que el paisaje sólo se entiende como medio percibido, en el peor sentido del término, es decir como una imagen sin sentido evaluada a los sumo con criterios estéticos y al que no atribuyen otros valores, para estos, que son los más, los topónimos no añaden nada y no los necesitan: quién no reconoce un roble no pasa de llamarlo árbol. Otros visitantes tienen intereses más definidos y la consecución de sus objetivos precisa de la toponimia: montañeros, escaladores, recolectores, aficionados a la arqueología, a la espeleología, cazadores, investigadores, estudiantes... Estos generalmente no tiene un conocimiento exhaustivo y cuando lo poseen es completamente ajeno a los valores campesinos y eso explica la parcialidad y estridencia de las nuevas toponimias. Para el campesino el topónimo dota de sentido al lugar al incluirlo en el discurso espacial global, construido sobre funciones y prácticas; para los visitantes no existe un discurso espacial global, sino discursos parciales, dispersos e inconexos que no buscan comprender el paisaje, sino localizar determinados hitos de su interés: las vías de escalada, las cuevas, las estaciones rupestres, los recorridos de montaña...

La anonimia espacial es casi absoluta para quienes sólo miran, pero los que hacen algo más que mirar necesitan nombres y cuando no los conocen se los inventan. Así el Barranco del Toril se convierte en el Barranco de Estoril (de establo a colonia de vacaciones), el Collado de los Bastianes ${ }^{43}$ pasa a ser el Collado del Dolmen (referencia culta), la Peña de la Brín- cola pasa a ser el Panderón (la parte por el todo), la Cinta del Fraile se convierte en los Tajos de las Alcandoras (asociación por contigüidad), la Huerta de Cándido "el Merguizo" en la Villa del Laurel (asentamiento romano), las Salas de Gabildo en Cuevas Negras (referencia a las sombras y el humo), el Vítor de Carlos III por el Mirador del Vito (por ignorancia del significado de 'vítor'), El Peñón de Acerrocobo en el Peñón Azul o la prosaica Nariz del Fraile en el poético Diedro del Sol. Este último cabe achacarlo a la nómina de los más diligentes en esta tarea, los escaladores, que han encontrado en los escarpes de Otiñar condiciones excelentes para la práctica de su deporte, $y$ en consecuencia han rebautizado numerosos parajes.

Es este el grupo de visitantes más interesante porque ha encontrado nuevos lugares y los ha integrado en un discurso espacial, con el que ha reterritorializado el paisaje de Otiñar, trasladándolo al espacio definido por las redes de información que conectan los diversos lugares de escalada a nivel mundial. De la visita de una sola de sus numerosas páginas web ${ }^{44}$ se desprende que distinguen 5 zonas: Otíñar (llaman así al Barranco de la Tinaja), el Frontón, el Vítor, el Salto de la Cabra (la Escaleruela) y los Tajos de las Alcandoras (la Cinta del Fraile). En algunas de ellas separan sectores, en el Frontón seis (Speerech, Cantos Gregorianos, Fakir, Tocho Grande, Tocho Pequeño, Ranofobia), que a su vez incluyen un número diverso de vías de escalada, cada una con su nombre que, generalmente, alude a películas (Misión Imposible, Gregorzenegger, Taxi Driver, Halcón Milenario), a grupos de Rock (Marilyn Manson, Pabellón Psiquiátrico, Eskorbuto, Parálisis Permanente), a videojuegos (Monkey Island, Espolón Comecocos), al sexo (Tau-

\footnotetext{
42 No hay que olvidar que los topónimos son discursos colectivos.

43 Chicote y López (1973:I I) explican este nombre propio que denomina tanto al collado como a las cuevas situadas al pie del mismo "por haber pertenecido a un pastor llamado Sebastián". La indagación de esta aseveración ha sido infructuosa y nadie conoce al tal pastor Sebastián, ni tampoco aparece como nombre de los libros de la parroquia de Santa Cristina. Podría tratarse de un error por homofonía y los Bastiones de la muralla que hay en el collado pasen, por incomprensión del topónimo, a ser Bastianes mucho más cercanos al universo pacífico de los últimos otiñeros. Sin embargo esto no pasa de ser una opinión sin mayor fundamento que una lógica discutible.

44 http://usuarios.lycos.es/atope/ cuyo webmaster es José Ramón Bellido.
} 
ritón, Desvirgación, Orgasmatrón, Mindarrecia), o a la experiencia inmediata (Todos Tus Muertos, Ya No Pincha, Sakabó el Aután, Julio Cagueta, Jubilación Anticipada). Estas referencias al imaginario que domina el tiempo libre de la juventud se extienden sobre los planos verticales del paisaje, cruzándolos con I I3, que sepa, nuevos topónimos. Como particularidad presentan que en su mayoría son aplicados a líneas de tránsito (las vías de escalada) que para los campesinos no existían. Esta es una clase especial entre los nombres de lugar: los topónimos paralelos, que Vieira (200 I) divide en originales (los creados espontáneamente por los usuarios), oficiosos (reconocidos en algunos documentos oficiales y que pueden llegar a ser oficiales), ex oficiales (antiguos topónimos resistentes) y correlatos (los que nacen paralelos a los oficiales). En este caso son una mezcla entre correlatos y originales al nacer o imponerse en determinados círculos ajenos al lugar sin tener en cuenta el topónimo existente.

El caso es que desde los años setenta del pasado siglo hay en marcha un conjunto de procesos de resemantización del paisaje, provocados por el desarrollo de múltiples y renovadas relaciones socio-económicas (profesoralumno, guía-turista, agencia de viajes-escalador, arrendatario del coto-cazador, etc.), que lo están convirtiendo en un cúmulo de nuevos lugares hasta ahora ocultos (vías de escalada, sitios arqueológicos, unidades geológicas, puestos de caza, etc.). Sin embargo son procesos parciales para los que parece no haber futuro, ya que sobre el paisaje planea la sombra de la parcelación urbanística, que, si se instaura como función dominante, provocaría el mayor de los impactos, disgregándolo hasta hacerlo intransitable. Esta circunstancia no se ha producido todavía (pese a un intento a principios de los ochenta que ha dejado unas pequeñas parcelas en la Fuente de la Olivilla), porque los vín- culos sentimentales del actual propietario se mantienen mediante la subvención europea del olivar, que hace rentable a la tierra como propiedad industrial. Cuando esta cese o cuando se mejore la capacidad circulatoria de la carretera de acceso y la tierra alcance más valor como propiedad financiera, por la especulación urbanística, que como propiedad industrial, será parcelada y vendida ${ }^{45}$. Y los nuevos propietarios, que habrán desembolsado sumas ingentes, procederán a vallar sin miramientos y no serán condescendientes con los viajeros esporádicos.

Es cierto que sobre esta tierra gravitan protecciones municipales, autonómicas y estatales que afectan al medio ambiente y al Patrimonio Histórico pero, como se sabe, estas serán insuficientes sin una concienciación ciudadana que, necesariamente, pasa por la apropiación integral del paisaje. Actualmente esto sólo se puede conseguir mediante la articulación de los diversos significados que otorga a este paisaje cada agente apropiador (incluido el urbanizador) en el discurso del Patrimonio Histórico como recurso (ZAFRA, 1999). Lo que permitiría una apropiación global del paisaje ${ }^{46}$ que, integrando las nuevas funciones y significados, volvería a restaurarse como signo de identidad, como marco de interrelaciones sociales y como fruto de una historia común.

\section{BIBLIOGRAFÍA}

ACOSTA NARANJO, R. (2000): "Palabras para los campos. Una aproximación al conocimiento del territorio en el Sur de Extremadura". Saber Popular. Revista extremeña de folklore, $\mathrm{n}^{\circ} \mid 5$.

AGUIRRE SADABA, F. J. y JIMÉNEZ, Ma C. (1979): Introducción al Jaén islámico (estudio geográfico-histórico). Instituto de Estudios Giennenses, Diputación Provincial de Jaén. Jaén.

\footnotetext{
45 Como prueba de lo expuesto, después de finalizar este trabajo, el I 3 de Enero de 2004 el Diario Jaén publicó la noticia de la intención municipal de realizar un Parque Temático del Aceite que contaría con tres sedes: La Imora, Jabalcuz y Otínar. Para Otíñar contempla la "recuperación" del poblado en ruinas pero "con carácter domótico", la construcción de un albergue rural, un centro de investigación, "rocódromos artificiales", una granja escuela y un campo de golf.

46 Como primer paso desde la Delegación Provincial de la Consejería de Cultura de la Junta de Andalucía se ha redactado un expediente para la inscripción de Otiñar en el Catálogo General del Patrimonio Histórico de Andalucía.
} 
ALCAZAR GONZALEZ, A. Y AZCARATE LUXAN, M.: "Aproximación a la toponimia del repertorio de caminos de Guadalajara". Actas del IV Congreso de Caminería Hispánica. (13-18 de julio de 1998). http://biblioteca2. uclm.es/biblioteca/ceclm/libros/camineria/C4/04fl5.htm (consultado el 3 de mayo de 2003).

ALCAZAR, E. (2003): El Concejo de Jaén en la Baja Edad Media: introducción al análisis del territorio y el poblamiento. Tesis doctoral de la Universidad de Jaén. Inédita.

AUGÉ, M. (1992): Los no-lugares. Espacios de anonimato. Una antropología de la sobremodernidad. Editorial Gedisa. Barcelona.

BASSO, K. H. (1984): "Westem Apache Place-Name Hierarchies". En E. Tooker y H.C. Conklin (coords.) Naming Systems. The American Ethnological Society. Washington D.C.

- (1996): Wisdom Sit In Places: Landscape An Language Among The Western Apache. New Mexico University.

BOAS, F. (1934): Geographical Names of the Kwakiutl Indians. Columbia University Contributions in Anthropology, $n^{\circ}$ 20. New York.

BUENO, G. (1987): Etnología y utopía. Júcar Universidad. Madrid.

BUENO, G. (1980): Imagen, símbolo, realidad (cuestiones previas metodológicas ante el XVI Congreso de Filósofos Jóvenes). El Basilisco n. 9: 57-74.

CARRERAS VELASCO, A. (1992): Jaén, 180 I - 1920. Estudio demográfico. Diputación Provincial de Jaén. Jaén

CASTELLS, M. ( I 987): La era de la información. Economía, sociedad y cultura. Vol. 2: El poder de la identidad, Madrid, Alianza

CAZABAN LAGUNA, A. ([19|4] |982): "La capilla del castillo de Jaén". Revista Don Lope de Sosa, 1914:54-59.

- ([19|4] |982): "La colonización del siglo XVI". Revista Don Lope de Sosa, 1916:77-79.

- ([19|4] 1982): "Lo que ocurría en el castillo de Jaén, en los tiempos en que, en Jaén, vivía Don Lope de Sosa". Revista Don Lope de Sosa, 1922:230-232.

CORONAS VIDA, L. J. (1994): La economía agraria de las tierras de Jaén (1500-1650). Universidad de Granada. Granada.

CRIADO BOADO, F. (1999): Del terreno al espacio: planteamientos y perspectivas para la Arqueología del Paisaje. C.A.P.A. 6. Universidade de Santiago de Compostela. Santiago de Compostela.

CUEVAS, J.; DEL ARCO, J. Y DEL ARCO, J. (200 I): Relación de los hechos del muy magnífico e mas virtuoso señor Don Miguel Lucas, muy digno Condestable de Castilla. Universidad de Jaén y Ayuntamiento de Jaén, Jaén.

CHICOTE UTIEL, M. Y LOPEZ MURILLO, J. (1973): "Nuevas pinturas rupestres en Jaén". Boletín del Instituto de Estudios Giennenses 19: 37-92.
ESLAVA GALAN, J., CEREZO MORENO, F. (1989): Castillos y atalayas del Reino de Jaén. Riquelme y Vargas Editores. Jaén.

FONTANA, J. (1984): La Historia. Análisis del pasado y proyecto social. Crítica. Barcelona.

FOUCAULT, M. ([1966] 1999): Las palabras y las cosas. Siglo XXI Editores S.A. $28^{a}$ edición en español. Madrid

- ([1969] 1970): La Arqueología del saber. Siglo XXI Editores S.A. México.

GOMEZ ORTIN, F. (1977): "El topónimo Escarihuela". Alquipir, revista de historia de Cehegín, año VII, nº 7: 9-II.

HERNANDO, A.(1999): "Percepción de la realidad y Prehistoria. Relación entre la construcción de la identidad y la complejidad socio-económica de los grupos humanos". Trabajos de Prehistoria vol. 56, n. 2.

HORKHEIMER, M. Y ADORNO, T. W. ([1944]1999): Dialéctica de la llustración. Círculo de lectores. Barcelona.

HUNN, E. (1994): "Place-names, Population Density, and the magic number 500". Current anthropolgy. Vol. 35: 8186.

LE-ROY LADURIE, E. ([1975] 198I): Montaillou, aldea occitana de 1294 a 1324. Taurus Ediciones, Madrid.

LÉVY, P. (1989): "La construction d'un système-expert", en Les chemins du virtuel, Simulation informatique et création industrielle, Cahiers du CCI numéro special, París, Editions du Centre Pompidou.

LOPEZ CORDERO, J. A. (1998): Historia ecológica de la comarca de Jaén. Ayuntamiento de Jaén. Jaén.

MADOZ, P. ([1845-1850] 1988): Diccionario GeográficoEstadístico-Histórico de España y sus Provincias de Ultramar. Madrid. Edición facsímil de Jaén por Ambito Ediciones S.A. Valladolid.

MARTINEZ DE MAZAS, J. ([1794] 1978): "Retrato al natural de la ciudad de Jaén y su término: su estado antiguo y moderno, con demostración de quanto necesita mejorarse su poblacion, agricultura y comercio". Edición Facsimil de la de Pedro de Doblas. Ed. Albir S.A., Barcelona.

MARX, K. Y ENGELS, F. ([I846] 1970): La ideología alemana. Editorial Grijalbo. Barcelona.

MOLES, A. A. Y ROHMER, É. ([1972] 1990): Psicología del espacio. Círculo de Lectores. Barcelona.

MONTOYA RAMIREZ, Ma. I. ( 1992): Alfonso XI. Libro de Montería. Estudio y edición crítica por Ma..l. Montoya Ramírez. Universidad de Granada. Granada.

MORENO, I. (1972): "El trabajo de campo etnológico y el problema de la elección de comunidad". Ethnica, n 3 : |65-180.

MURPHY, M. Y GONZALEZ FARACO, J. C. (1996): "Masificación ritual, identidad local y toponimia en El Rocío". Demófilo: Revista de Cultura Tradicional de Andalucía:20:101-119. 
OLIVARES BARRAGAN, F. (1988): "Castillo de Otínar". Senda de los Huertos $n^{\circ} 13$.

OLMO LOPEZ, A. (200 I): La subbéticas islámicas de Jaén y granada. Evolución territorial. De los antecedentes romanos a la conquista cristiana. Instituto de Estudios Giennenses, Diputación Provincial de Jaén. Jaén.

OLSON, D. R. ([1994] 1998): El mundo sobre el papel: el impacto de la escritura y la lectura en la estructura del conocimiento. Barcelona. Gedisa.

PITT-RIVERS, J. A. ([1954] 197I): Los hombres de la Sierra. Ensayo sociológico sobre un pueblo andaluz. Editorial Grijalbo. Barcelona.

QUESADA QUESADA, T. (1994): El paisaje rural de la campiñpa de Jaén en la Baja Edad Media según los Libros de las Dehesas. Universidad de Jaén. Jaén.

RODRIGUEZ MOLINA, J. (I982): "Jaén. Organización de sus tierras y hombres (s. XIII-XV)". En J. Rodríguez Molina (Coord) Historia de Jaén. Diputación provincial de Jaén; Colegio Universitario de Jaén. Jaén.

RUIZ RODRIGUEZ, A.; Molinos Molinos, Manuel y Risquez Cuenca, Carmen (200 I): "Paisaje y territorio mundo". Arqueología Espacial.

SALVATIERRA CUENCA, V. (200I): La crisis del Emirato Omeya en el Alto Guadalquivir. Precisiones sobre la geografía de la rebeión muladí. Universidad de Jaén. Jaén

SALVATIERRA CUENCA, V. (1995): "Castillo de Otínar" en V. Salvatierra (ed.) Guía arqueológica de la Campiña de Jaén. Sierra Nevada 95- El Legado Andalusí, Granada.
TORT DONADA, J. (2000): "Toponimia y territorio. Los nombres de los núcleos de población de la comarca del Baix Camp, Tarragona, desde una perspectiva onomasiológica". Scripta Nova No 67. Revista Electrónica de Geografía y Ciencias Sociales. Universidad de Barcelona. http://www.ub.es/geocrit/sn-67.htm 01/07/00

- (200 I): "La toponímia com a camp de coneixement interdisciplinari. Algunes bases teóriques i epistemológiques per l'estudi dels nom de lloc". Scripta Nova No 67. Revista Electrónica de Geografía y Ciencias Sociales. Universidad de Barcelona. http://www.ub.es/geocrit/sn-86.htm $0 \mid / 04 / 01$

VARGAS, I. (1990): Arqueología, Ciencia y Sociedad. Editorial Abre Brecha. Caracas.

VIEIRA, Z. P. (200I): "O reflexo da memória social na toponímia:o espontâneo e o popular". http://www.filologia.org.br/venlf/anais\%20v/civ2_| 3.htm Colgado el 28/I I/0 I, consultado 24/03/2003.

ULLMANN, S. ([1962] 1967): Semántica. Introducción a la ciencia del significado. Madrid. Aguilar.

V. AA. (1987): Itinerario geológico y botánico por las Sierras al Sur de Jaén. Universidad de Granada y Consejería de Educación y Ciencia de la Junta de Andalucía. Granada.

WAGNER, R. (1986). Symbols that Stand for Themselves. University of Chicago Press. Chicago.

ZAFRA DE LA TORRE, N. (1999): "El patrimonio arqueológico como recurso socio-económico: El proyecto Otíñar". Sumuntan, Revista de Estudios sobre Sierra Mágina, 11. Jaén. 


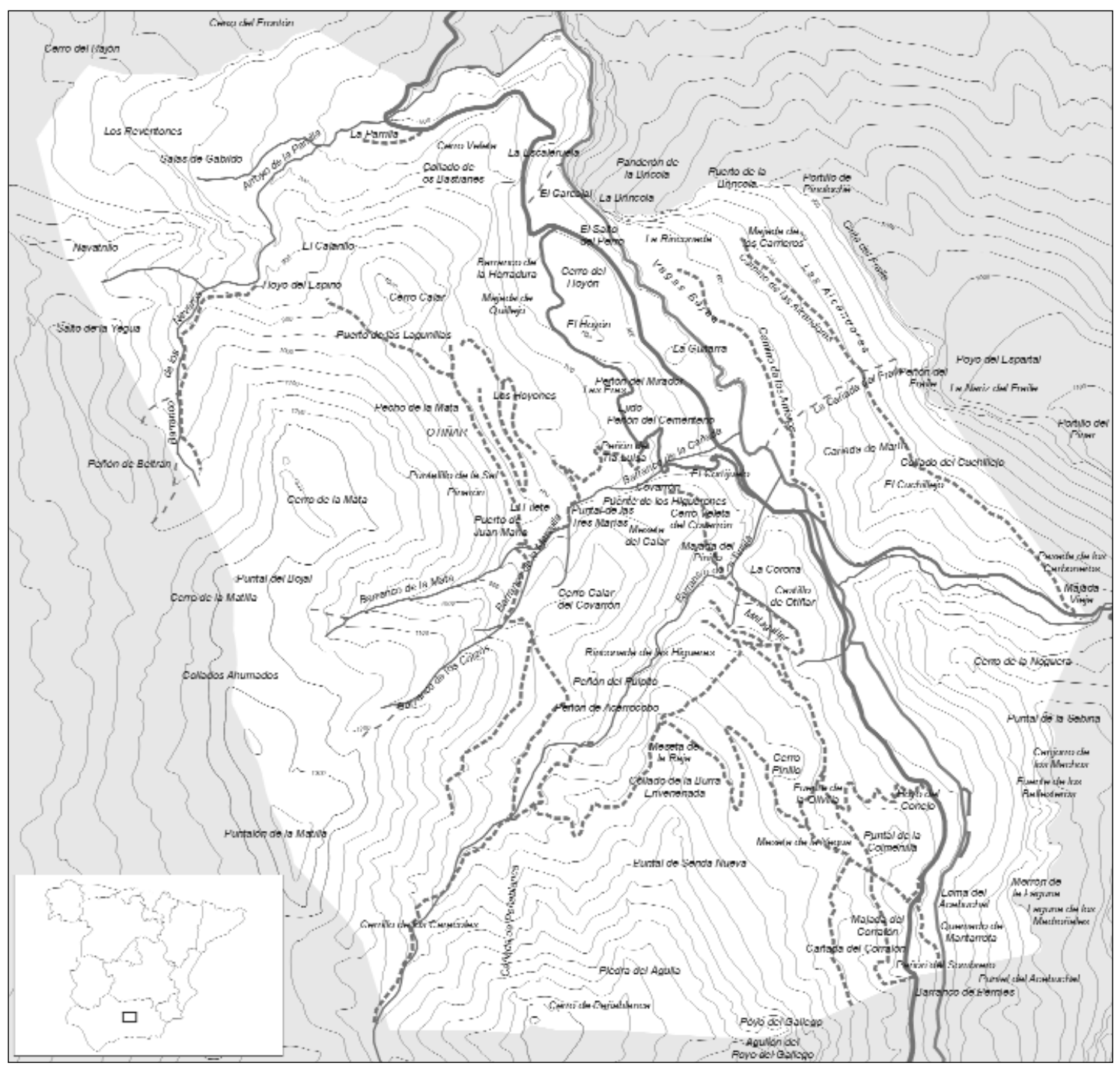

Fig. I. Plano general de la zona con la toponimia

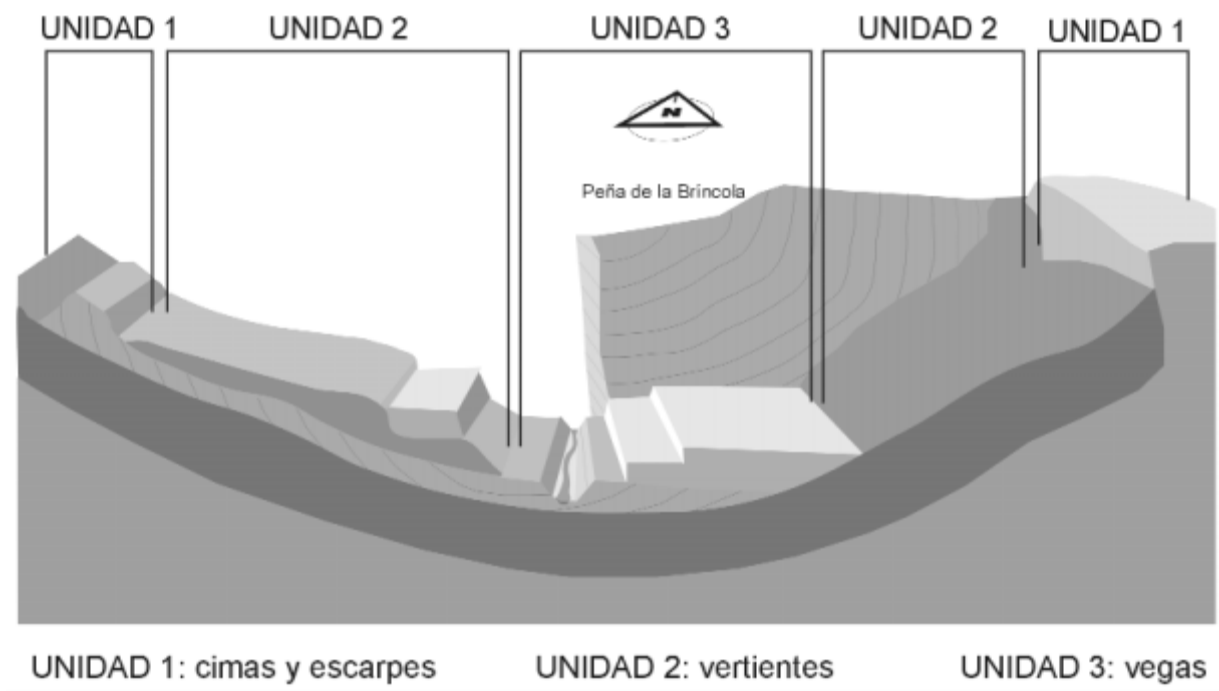

Fig. 2. Unidades del relieve en el valle de Otíñar 


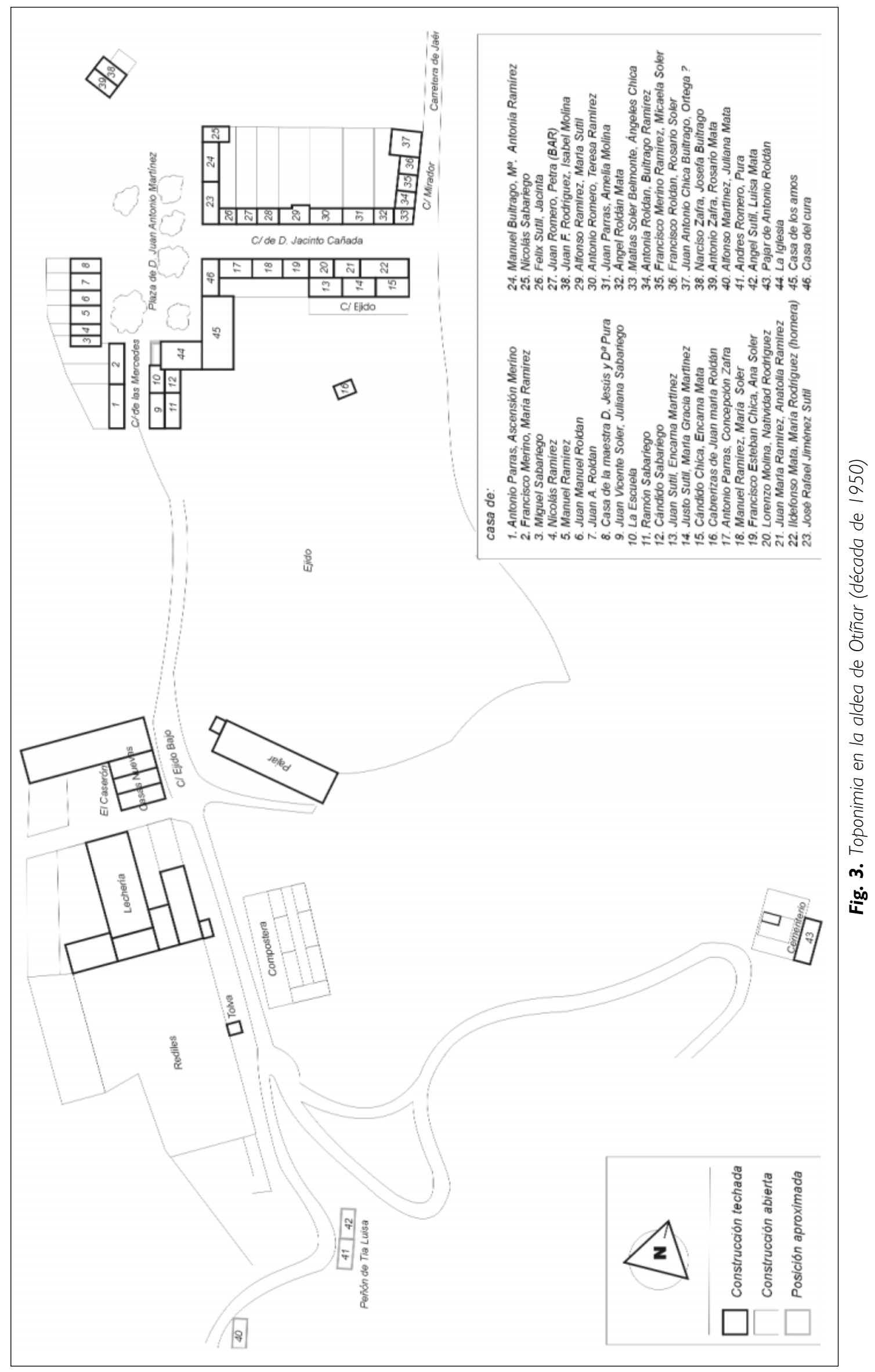




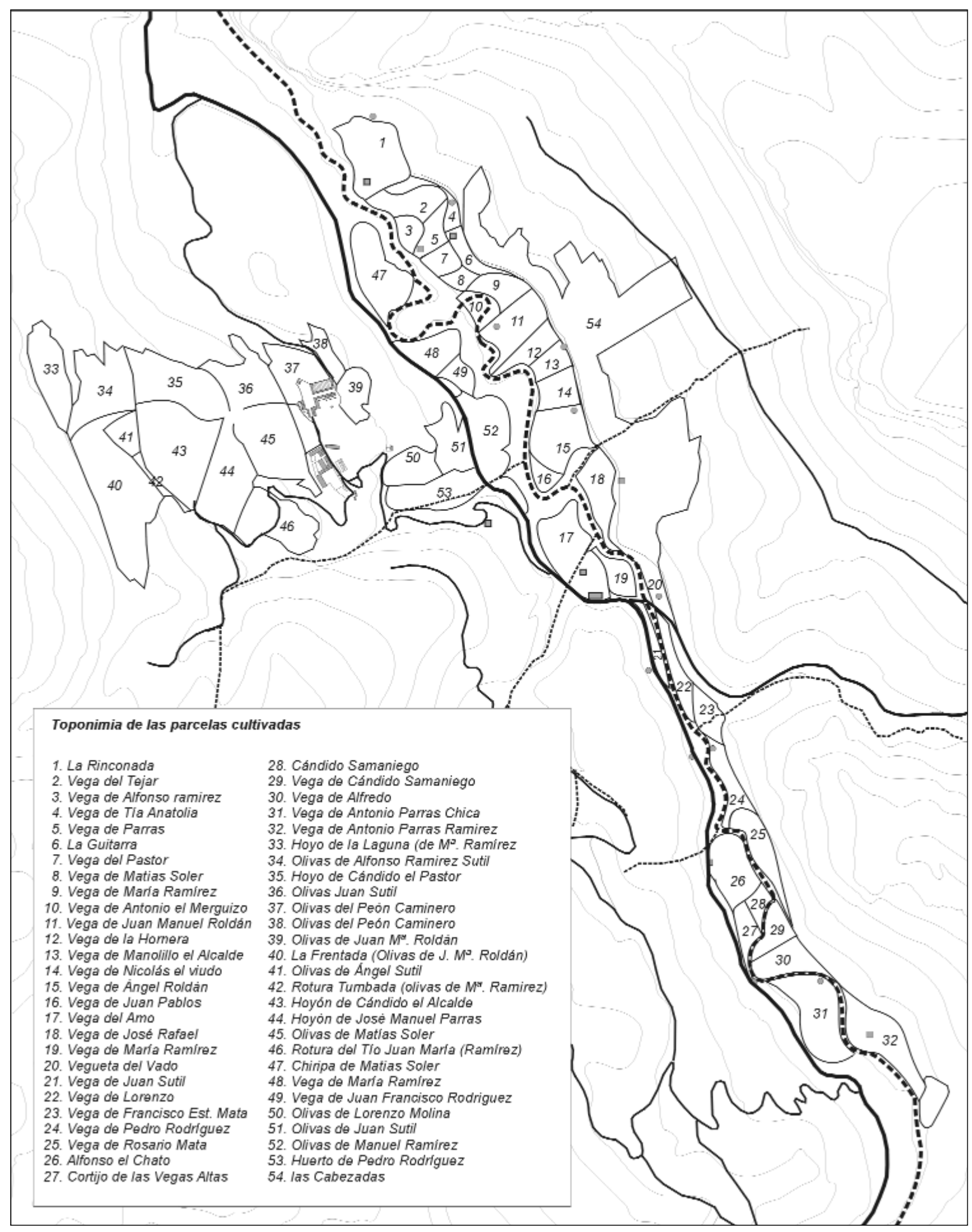

Fig. 4. Toponimia de las parcelas cultivadas en el valle de Otiñar 


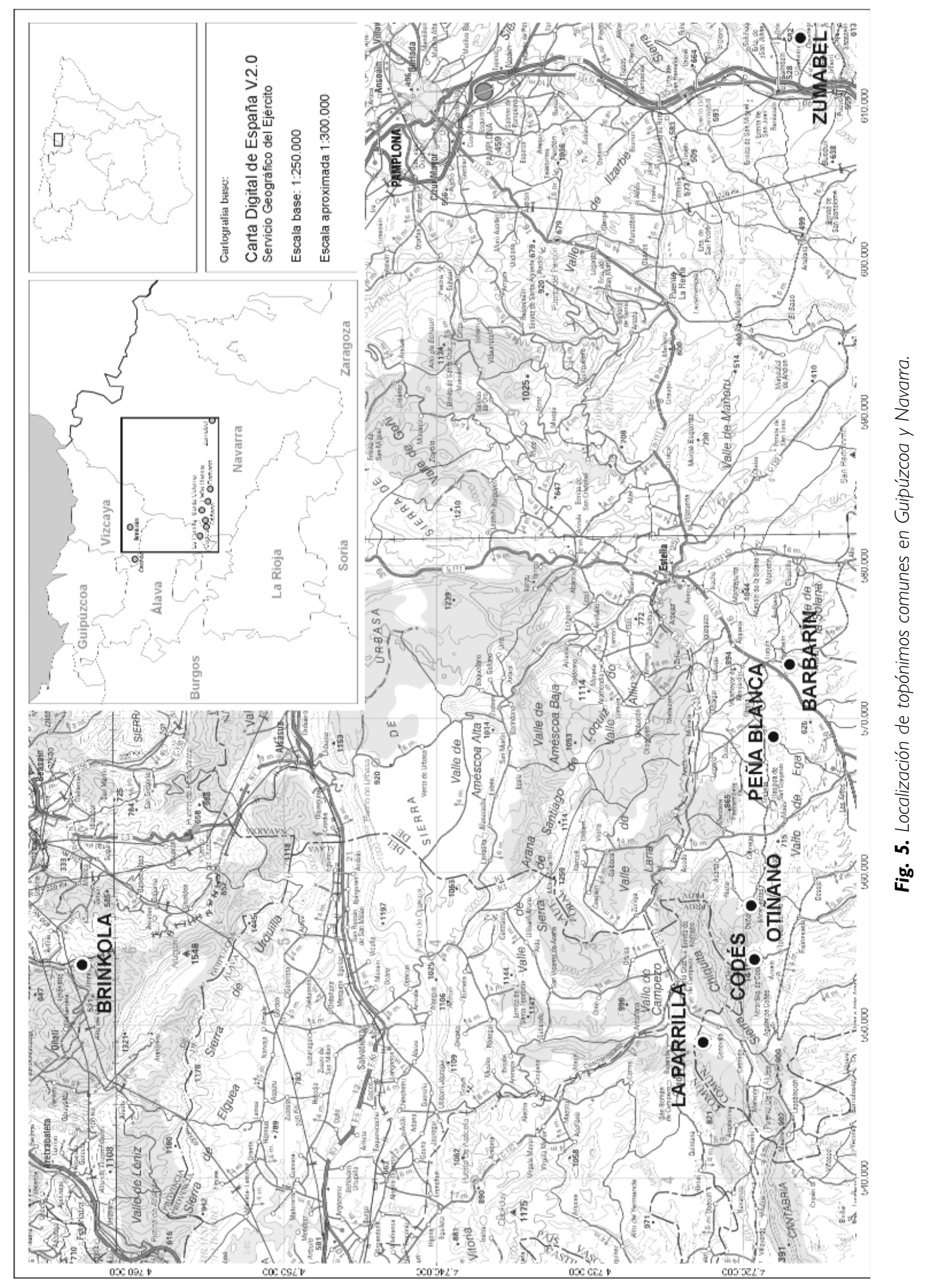




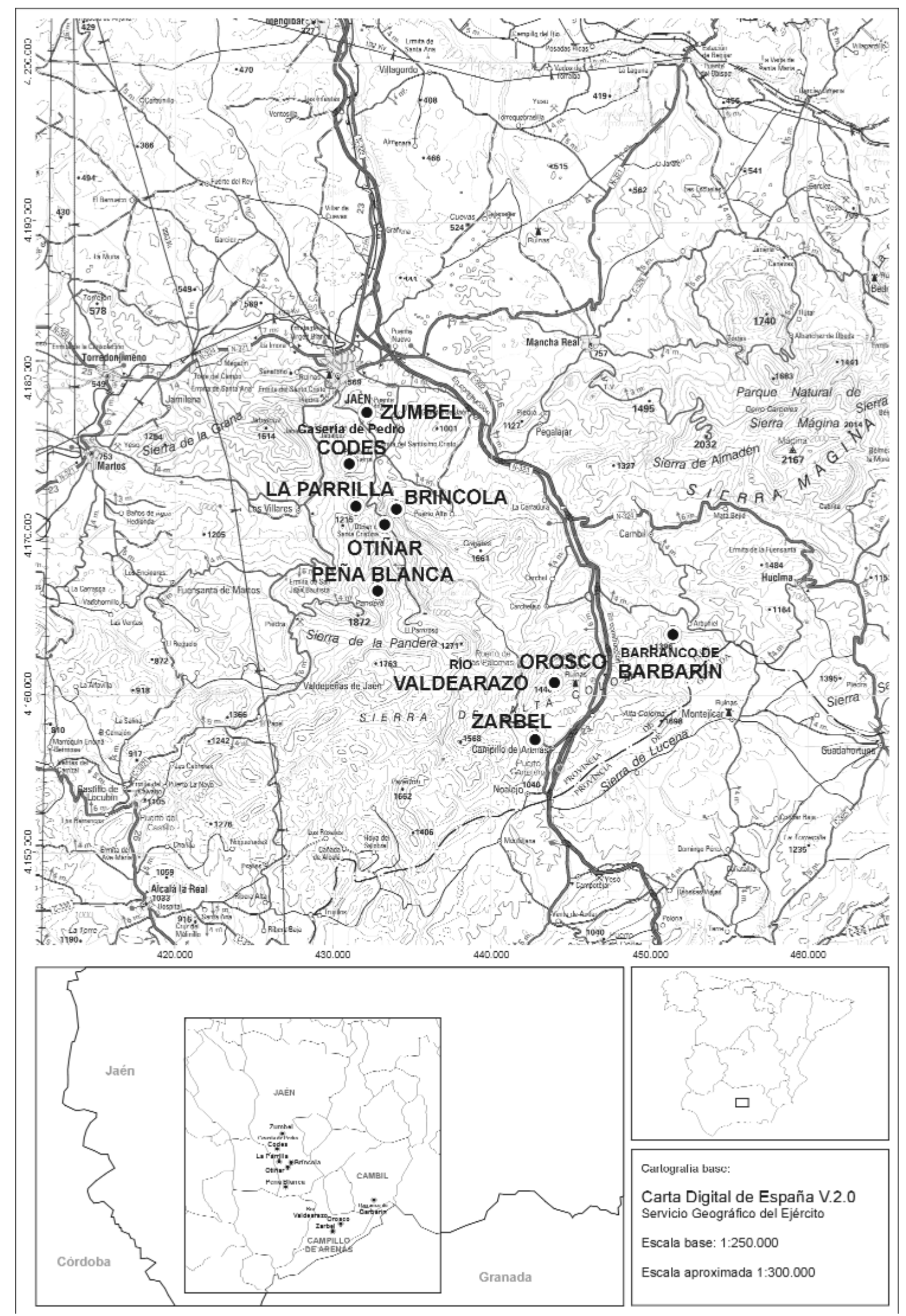

Fig. 6. Localización de topónimos comunes en Otíñar y el entorno de la Sierra Sur. 


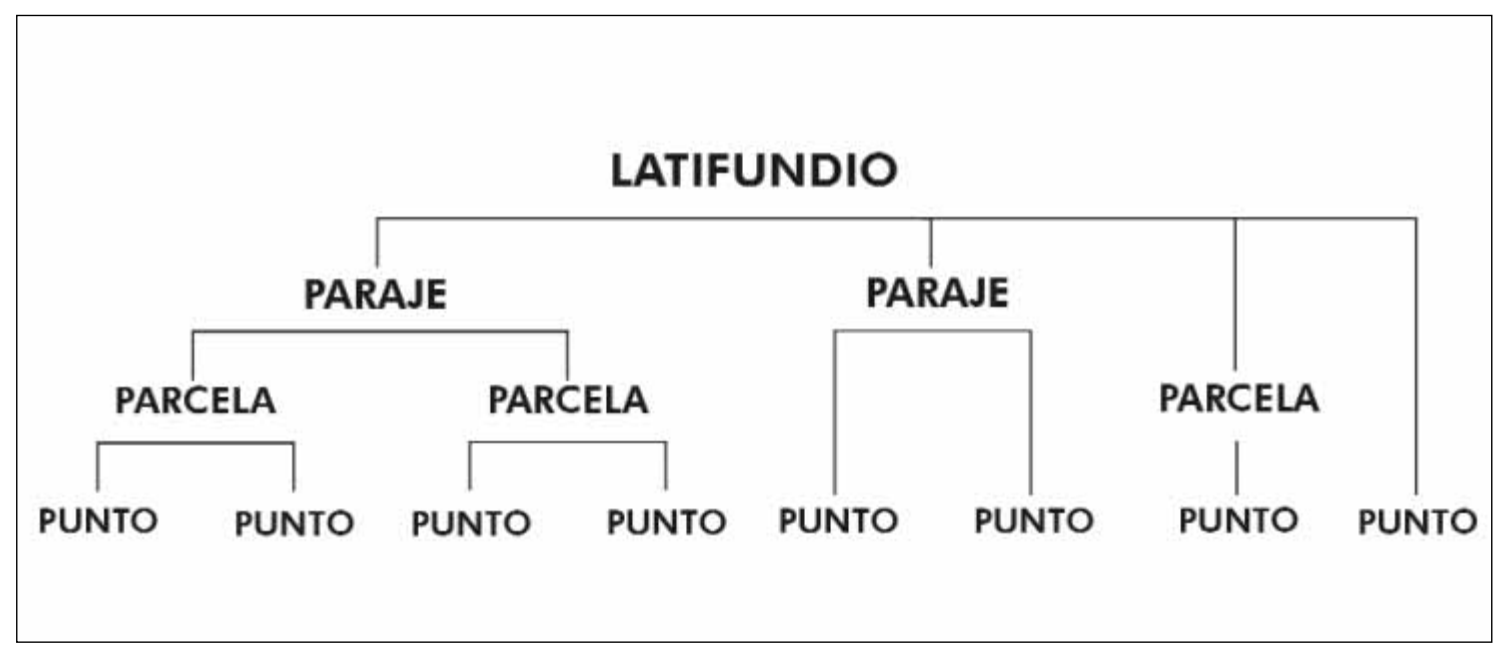

Fig. 7. Esquema de la organización escalar de los espacios significativosde Otiñar. 